\title{
Deep Eutectic Solvents for the Valorisation of Lignocellulosic Biomasses towards Fine Chemicals
}

\author{
Enrico Scelsi, Antonella Angelini and Carlo Pastore *(D) \\ Water Research Institute (IRSA), National Research Council (CNR), Via F. de Blasio 5, 70132 Bari, Italy; \\ enrico.scelsi@ba.irsa.cnr.it (E.S.); antonella.angelini@ba.irsa.cnr.it (A.A.) \\ * Correspondence: carlo.pastore@ba.irsa.cnr.it
}

Citation: Scelsi, E.; Angelini, A.; Pastore, C. Deep Eutectic Solvents for the Valorisation of Lignocellulosic Biomasses towards Fine Chemicals. Biomass 2021, 1, 29-59. https:// doi.org/10.3390/biomass1010003

Academic Editor: S David Jackson

Received: 17 May 2021

Accepted: 8 July 2021

Published: 12 July 2021

Publisher's Note: MDPI stays neutral with regard to jurisdictional claims in published maps and institutional affiliations.

Copyright: (c) 2021 by the authors. Licensee MDPI, Basel, Switzerland. This article is an open access article distributed under the terms and conditions of the Creative Commons Attribution (CC BY) license (https:/ / creativecommons.org/licenses/by/ $4.0 /)$.

\begin{abstract}
The growing demand for energy and materials in modern society pushes scientific research to finding new alternative sources to traditional fossil feedstocks. The exploitation of biomass promises to be among the viable alternatives with a lower environmental impact. Making biomass exploitation technologies applicable at an industrial level represents one of the main goals for our society. In this work, the most recent scientific studies concerning the enhancement of lignocellulosic biomasses through the use of deep eutectic solvent (DES) systems have been examined and reported. DESs have an excellent potential for the fractionation of lignocellulosic biomass: the high H-bond capacity and polarity allow the lignin to be deconvolved, making it easier to break down the lignocellulosic complex, producing a free crystallite of cellulose capable of being exploited and valorised. DESs offer valid alternatives of using the potential of lignin (producing aromatics), hemicellulose (achieving furfural) and cellulose (delivering freely degradable substrates through enzymatic transformation into glucose). In this review, the mechanism of DES in the fractionation of lignocellulosic biomass and the main possible uses for the valorisation of lignin, hemicellulose and cellulose were reported, with a critical discussion of the perspectives and limits for industrial application.
\end{abstract}

Keywords: deep eutectic solvents; lignocellulosic pretreatment; lignin valorisation; cellulose valorisation; HMF; furfural; aromatics; 5-(chloromethyl) furfural

\section{Lignocellulosic Biomass: Main Components and Structures}

Lignocellulosic biomass is the most plentiful renewable carbon-based resource on Earth. It has been regarded as the most promising starting material for the expression of the biorefinery concept [1]. Lignocelluloses, such as agricultural scraps, forest residues, herbaceous and woody energy crops and dedicated crops, are rich, inexpensive and renewable, which could make them an alternative for fossil resources [2]. Apart from minor constituents, lignocellulosic biomass is mainly made up of three biopolymers (i.e., cellulose, lignin and hemicelluloses). Cellulose, hemicellulose and lignin constitute $90 \%$ of the dry weight of a plant. Among these, both cellulose and hemicelluloses consist of C5 and C6 sugars. They could be effectively converted into fermentable sugars, while lignin is made up of phenylpropanoid units connected by C-C and ether bonds. In detail, lignin acts as a barrier for the hydrolysis of cellulose and hemicellulose, which are interconnected for forming a complex supramolecular network bound together through several covalent and secondary chemical bonds. More than $70 \%$ of the total biomass comprises polymeric carbohydrates and phenolic lignins [3]. Among the minor components, chlorophyll, resins, terpenoids and inorganic components are worthy of being cited. The physicochemical properties of specific biomass significantly depend on the concentration and nature of the main ingredients (cellulose, lignin and hemicellulose) (Figure 1). 


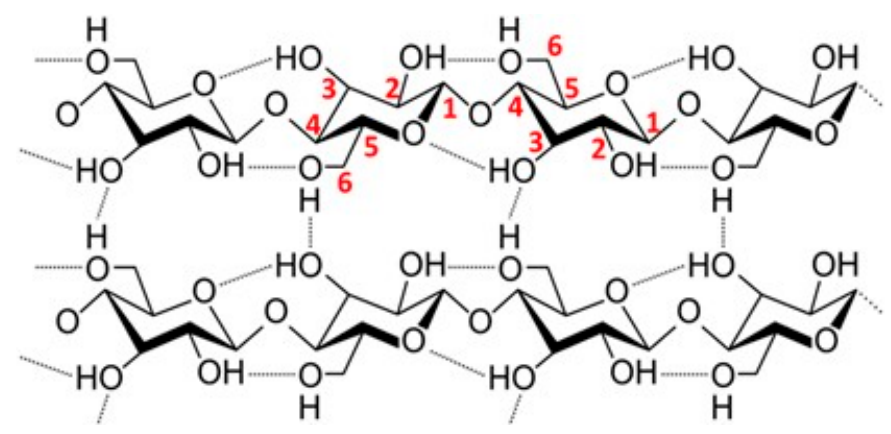

(a)

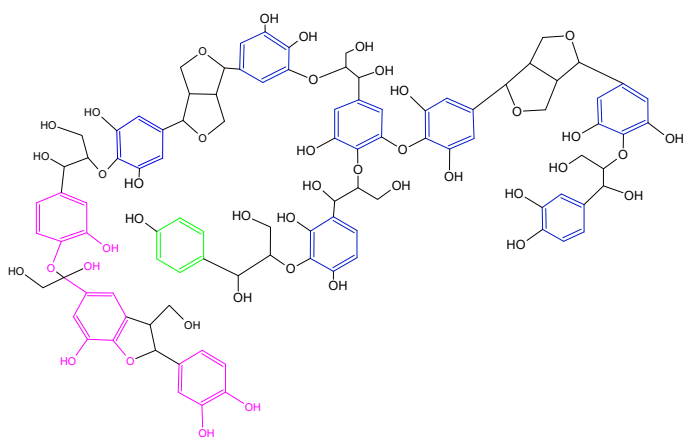

(b)

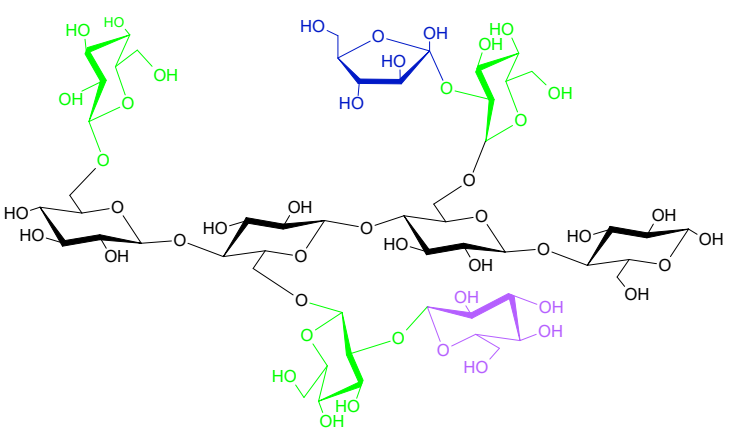

(c)

Figure 1. Representation of molecular structures of (a) cellulose, (b) lignin (syringol subunits in blue, guaiacol in violet and p-hydroxyphenyl in green) and (c) hemicellulose (glucose units in black, xylose in green, galactose in violet and arabinose in blue).

Cellulose, the primary component of biomass, has a robust molecular structure of long chains of glucose units. The monomeric glucose units are joined by $\beta-(1,4)$ glycosidic linkages (Figure 1a). Hydrogen bonding and van der Waals interactions generate the cellulose structure of microfibrils organised in parallel stacks. Consequently, these cellulosic microfibrils, which have both amorphous and crystalline regions, are connected with the hemicellulose and lignin to constitute macrofibrils. Hydrogen-bonded cellulose chains are organized in a secondary structure in which each chain interacts with the other through hydrophobic or van der Waals forces and hydrogen bonds. These well-organized structures, built on additional hydrogen bonding, make the cellulose very difficult to be broken through thermochemical treatment. On the other hand, it is readily hydrolysed by specific enzymes (cellulases). The valorisation of cellulose could be easily achieved by using these enzymes, which are capable of demolishing the polymeric structures by producing glucose. Glucose represents a platform molecule for the obtainment of renewable liquid fuel, biomaterials and fine chemicals.

Lignin is the second most abounding biopolymer on Earth. It is made up of repetitive units of coumaryl (H), coniferyl (G) and sinapyl alcohols (S) (Figure 1b). These polymeric units (monolignols) form a layer that provides support to the plant membrane. They are bounded to each other through several covalent carbon-carbon and aryl ether bonds obtained via radical polymerization/condensation (Figure 2). 
<smiles>COc1cc(/C=C/CO)ccc1O</smiles><smiles>COc1ccc(C(C)Oc2ccccc2)cc1</smiles><smiles>Cc1ccc(OCC(C)C)cc1</smiles><smiles>COc1ccc(C)cc1-c1c(OC)cccc1OC</smiles><smiles>Cc1ccc(Oc2cc(C)ccc2O)cc1</smiles><smiles>COc1ccc([C@@H]2Oc3ccccc3[C@@H]2C)cc1</smiles><smiles>[B]C1COCC1[B]</smiles><smiles>COc1ccc(C=C(C)C(C)(C)C)cc1</smiles>

Figure 2. Lignin subunit structures of p-coumaryl alcohol $(\mathrm{H})$, coniferyl alcohol $(\mathrm{G})$ and sinapyl alcohol (S) and the primary two-dimensional type of bonds ( $\beta-\mathrm{O}-4,-\mathrm{O}-4,4-\mathrm{O}-5,5-5, \beta-5, \beta-1$ and $\beta-\beta)$ present in the lignin [4].

Lignins can be classified into three main classes: hardwood, softwood and herbaceous lignin. Softwoods generally contain the highest lignin content (25-31 wt. \%), followed by hardwoods (16-24 wt. \%) and herbaceous crops (16-21 wt. \%). Additionally, the relative content of the monolignols varies significantly among the three biomass kinds. Softwood is mainly composed of $\mathrm{G}$ units ( $>95 \%$ ), hardwood is made up of $\mathrm{G}$ and $\mathrm{S}$ units and herbaceous crops contain H, G and S units [5].

Hemicellulose is a polysaccharide composed of pentoses (arabinose and xylose), hexoses (glucose, galactose and mannose) and sugar acids. These units are linked together through glycosidic and fructose ether linkages and form branched polymeric structures. As opposed to cellulose, hemicellulose is more prone to be broken down into monomeric units via mild thermochemical treatments due to the lower degree of polymerization and inferior crystallinity [6]. Hemicellulose refers to a diverse class of noncellulosic polysaccharides that are also present within plant cell walls. Hemicelluloses play an essential role in strengthening plant cell walls by tethering cellulose microfibers together. Sidechains introduced by substitutions on the hemicellulose backbone can modify the hydrophobicity of hemicelluloses, thus altering the interactions of hemicelluloses with cellulose and lignin, which enables hemicelluloses to adapt to particular cell walls. For instance, the substitution of hydrophilic arabinosyl residues on a xylan backbone results in xylan exhibiting a different binding preference than acetylated xylan, whose hydrophobic acetyl functional groups have a higher propensity to reduce the $\mathrm{H}$-bonding with water and enhance the interactions with lignin. In contrast to cellulose, which has the same molecular structure and composition in all plants, the monomeric composition and molecular connectivity of hemicellulose varies substantially between different species [7]. 
In conclusion, cellulose, lignin and hemicellulose can be seen as valuable sources of simple sugars and aromatics. Simple sugars and aromatics could represent the primary feedstock to feed the future biorefinery for producing fuels, materials and fine chemicals from renewable sources. However, the complex crosslinked structure and the recalcitrant nature of lignocellulose are the major hindrances to a successful direct conversion into valuable chemicals. Even the most efficient route, namely the biological degradation, is not efficient in demolishing virgin biomasses. The crystallinity of cellulose, the degree of polymerization of lignin, the particle size, the pore size, the volume and the complexity of biomass constituents are responsible for the recalcitrance of lignocellulosic biomass [8]. In detail, the complexity of biomass is due to the interconnection of lignin and cellulose, mediated by covalent bonds with hemicelluloses, strongly stabilized by steric H-bonding (Figure 3) to constitute the lignocellulosic complex (LCC).
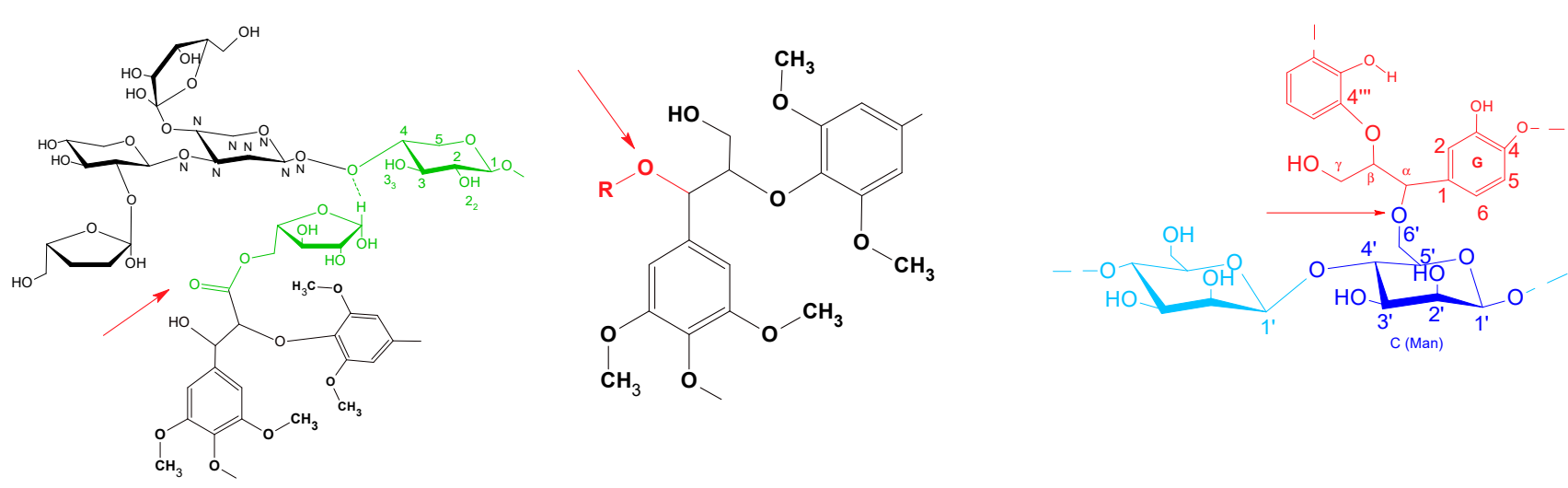

Figure 3. Examples of covalent bonds between hemicellulose and lignin stabilized by supramolecular H-bond interaction.

Purified LCC fragments were isolated (using mannanase and a polyvinyl gel affine to lignin) and analysed (HMBC and ${ }^{13} \mathrm{C}$-edited TOCSY-HSQC analyses). An $\alpha$ ether bond between the C- 6 position of the $\beta$-mannose and the $\alpha$ position of lignin was detected through a correlation signal. This characterization study offers a precious element for understanding the plant cell wall structures and the roles of lignin-cellulose bonds in the physical properties of cell walls. This kind of investigation represents the first step towards the development of new conversion technologies for biomass valorisation through component separation [9]. In this sense, delignification and removal of hemicellulose are the key points to be addressed, possibly avoiding the release of molecules that could inhibit enzymes' subsequent action, such as levulinic acid, 5-hydroxymethylfurfural (HMF), etc.

For this reason, a pretreatment step is necessary to demolish such supramolecular interactions. Traditional methods involve highly impacting chemical treatments (for example, acid/alkaline hydrolysis) [10]. The aims of the hydrolytic acid/alkaline treatments are to increase the digestibility of sugar substrates by breaking the covalent bonds that bring together cellulose, lignin and hemicellulose, solubilizing hemicellulose and part of lignin and making the cellulose more accessible to microorganisms/enzymes that can catalyse the production of simple sugars. The subsequent step, after the pretreatment, can be the fermentation of sugars to produce biofuels (ethanol and butanol). Chemical pulping for producing pure cellulose in paper mills is not appropriate to this aim since inhibitors are typically released, and the subsequent demolition of cellulose can be carried out only after an expensive washing, generating a large amount of waste and wastewater [11].

Many studies have been conducted to optimize treatments of lignocellulose to enhance its digestibility $[12,13]$. Several methods were investigated, such as hot water [6], supercritical fluid $\left(\mathrm{sCO}_{2}\right)[14,15]$ and ionic liquid (IL) [16,17], and combined pretreatment methods [18-20] have been developed to optimize the performances and the processing costs. To avoid using non-ecofriendly chemical products (such as ILs [21-26]) in biomass 
enhancement processes, in recent years, new, more environmentally friendly solvents have been more extensively used: deep eutectic solvents (DES).

\section{Deep Eutectic Solvents (DES)}

\subsection{Definition of DES}

Considered as green evolutions of ILs [27], DESs are obtained upon mixing two compounds in such a ratio that the resulting mixture has a significantly lower melting point than that of each constituent (Figure 4).

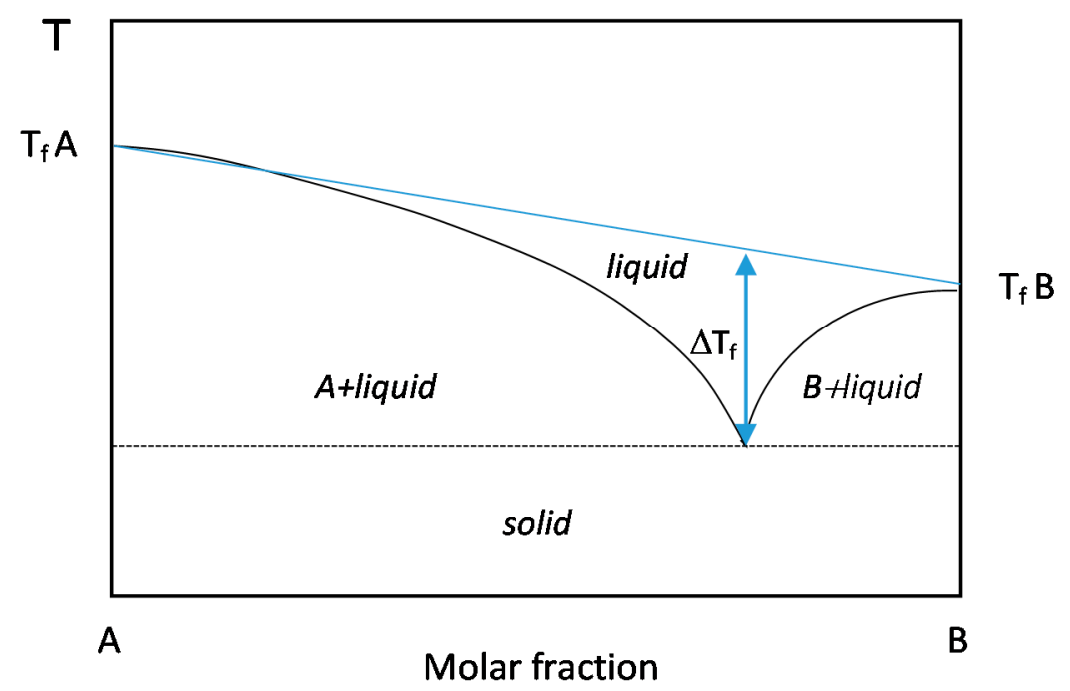

Figure 4. Phase diagram representation of the eutectic point at two components.

The classic example of a DES is the eutectic mixture formed by choline chloride $(\mathrm{ChCl})$ and urea with a molar ratio of $1: 2$, which exhibited a freezing point of $12{ }^{\circ} \mathrm{C}$, which is considerably lower than that of $\mathrm{ChCl}\left(302^{\circ} \mathrm{C}\right)$ and urea $\left(133^{\circ} \mathrm{C}\right)[28,29]$. DESs are prepared by combining hydrogen bonding donors (HBD, such as amines, amides, carboxylic acids and polyols) and hydrogen bonding acceptors (HBA, e.g., the counterion of quaternary ammonium salt) to form eutectic mixtures. Typically, this results from the interaction among these components: the stronger the interaction, the higher the difference of melting point with respect to the ideal melting temperature of the mixture (Figure 5).
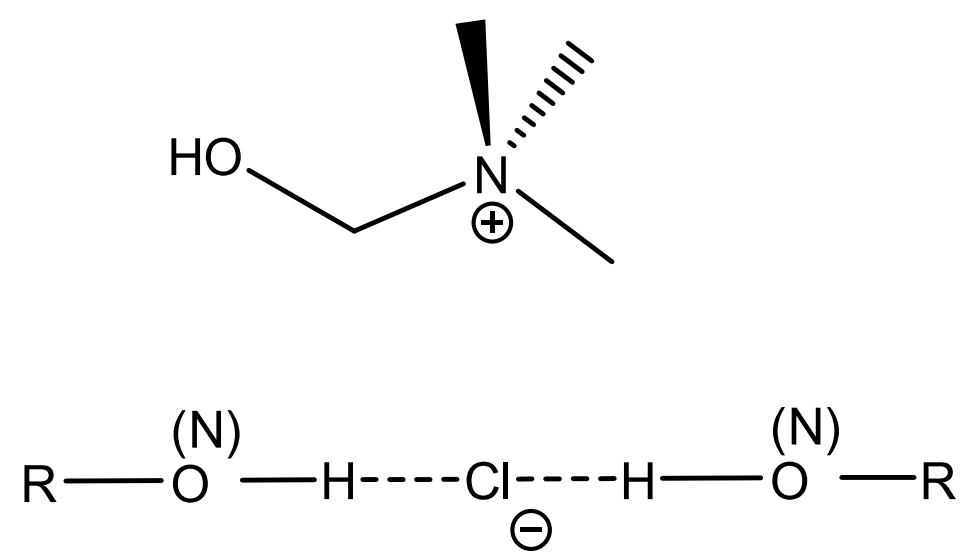

Figure 5. Interaction of generic $\mathrm{HBD}$ onto the counterion of $\mathrm{HBA}(\mathrm{ChCl}$ in this case).

The melting temperature of DESs depends on the starting components and their reciprocal molar ratio. The decrease in the melting point of DESs is attributed to the delocalization of charge resulting from hydrogen bonding between HBD and HBA. A 
higher hydrogen-bonding capability of the mixture will bring a more significant decrease in the melting point of the DES. According to the classification made by Abbott [29], DES are divided into four types:

Type I: Combination of organic salts and nonhydrated metal halides;

Type II: Combination of organic salts and metal hydrates;

Type III: Mixture of organic salts and compounds being hydrogen bond donors;

Type IV: Combination of metal chlorides and compounds being hydrogen bond donors.

DESs of Type I contain metal halides $\left(\mathrm{SnCl}_{2}, \mathrm{ZnCl}_{2}\right.$ or $\left.\mathrm{FeCl}_{3}\right)$ and an organic salt, most frequently a quaternary ammonium salt, IL included. DESs of Type II are obtained from the combination of an organic salt and hydrated metal salts. This eliminates problems with sensitivity to moisture, allowing their use to be extended to an industrial scale. DESs of Type III are composed of organic salts and an HBD, including amides, carboxylic acids and alcohols (Figure 6).

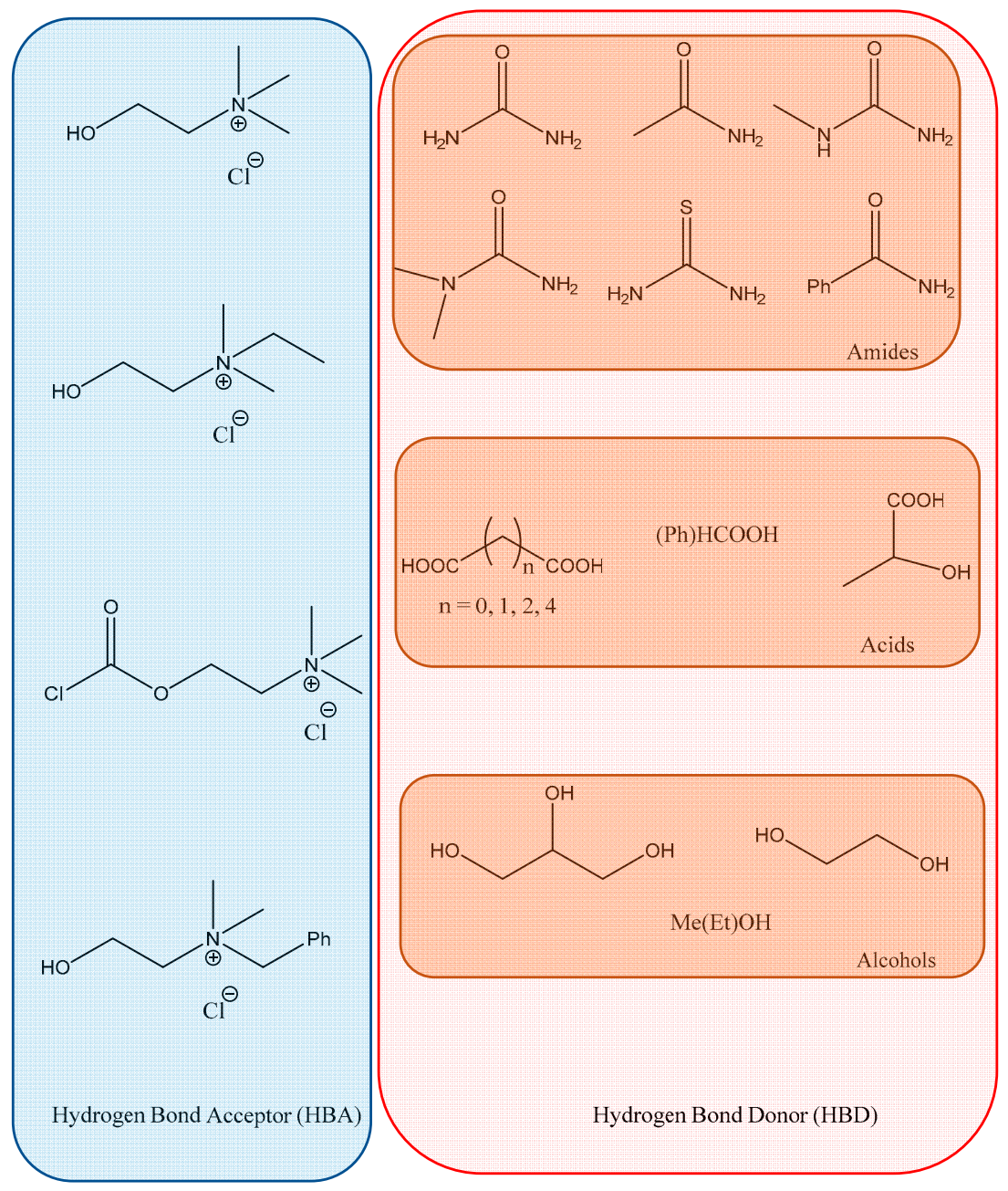

Figure 6. Examples of HBAs and HBDs usually adopted for preparing DES for the valorisation of biomasses.

Their advantage lies in a simple preparation and nonreactivity with water. DESs of Type IV are composed of metal salt instead of organic salt.

\subsection{DES Preparation and Physicochemical Properties}

The synthesis of DES could be conducted via several methods:

- Heating up, under constant agitation, the DES components to obtain a clear liquid solution; 
- $\quad$ Removal of the solvent (typically water) through evaporation up to the remainder of the DES components initially dissolved therein;

- Removal of the solvent through freeze-drying from HBA and HBD solutions, up to the remainder of the individual components of the DES;

- Continuous feeding of the DES components into a heated extruder until a solution is obtained.

The physicochemical properties of DESs primarily depend on the composition and the molar ratios of HBA and HBD. At standard conditions, DES density is in the range $800-1600 \mathrm{~kg} \mathrm{~m}^{-3}$. Density decreases with the increase in the alkyl chains in the components of the mixture (Table 1).

Table 1. Physicochemical properties of DES.

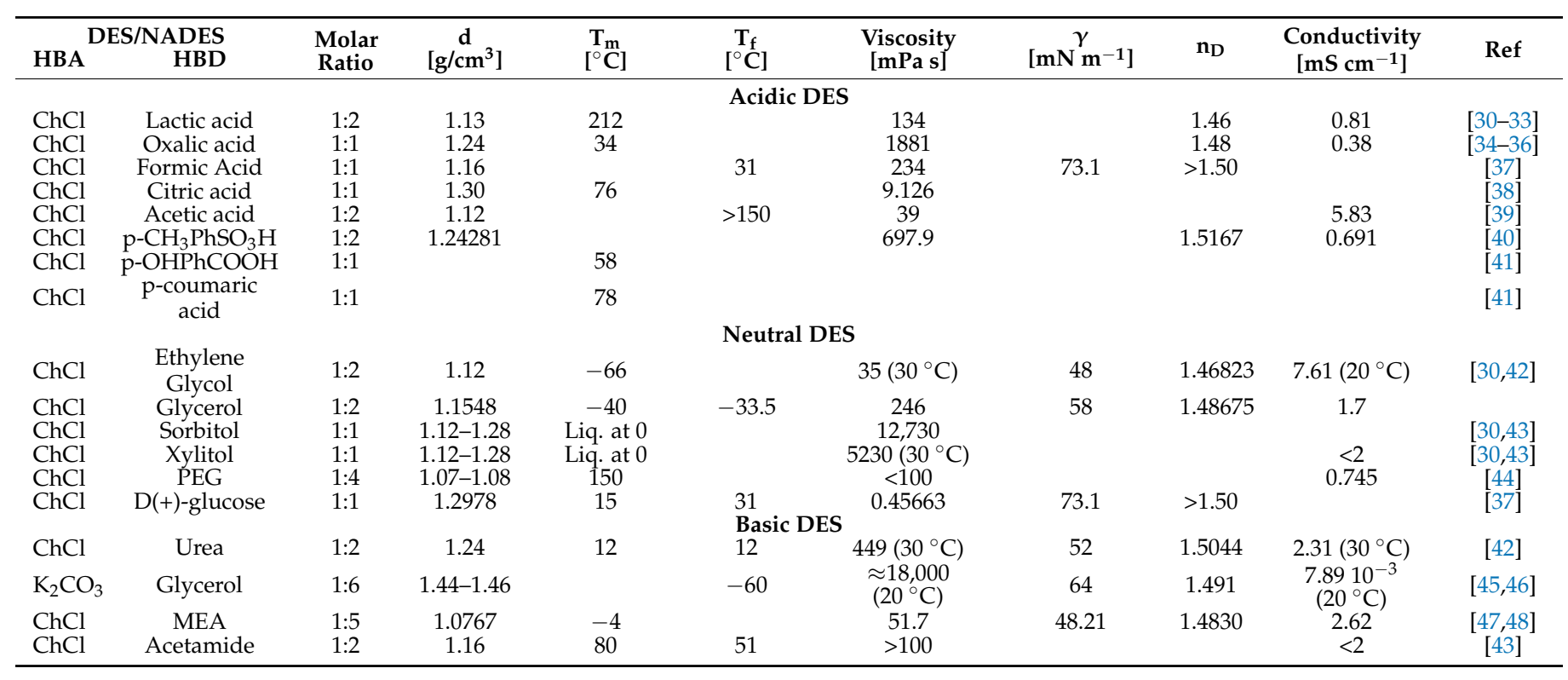

Table 1 shows the main physicochemical properties of the most diffusely used DES: density (d), melting temperature (Tm), freezing temperature (Tf), viscosity, surface tension $(\gamma)$, refractive index $(\mathrm{nD})$ and conductivity. $\mathrm{ChCl}$ is the most extensively used HBA for its capability to form a DES with several HBDs [49]. DESs may have properties similar to ILs but are cheaper to produce due to the lower cost of the HBDs and HBA and the simple preparation.

In general, DESs are nonvolatile, nonflammable and miscible with water. They have a high viscosity (>100 $\mathrm{mPa}$ ) at room temperature, but upon increasing the temperature of DESs, their viscosity decreases; in industrial applications, DESs having low viscosity are desirable considering the economic and technical benefits associated with the downstream processing. Adding water may represent an option for decreasing the viscosity when low viscosity is essential. Most DESs are hygroscopic and absorb moisture from the air. When water is added to the DES, all HBDs and HBAs are hydrated. Small anions, such as halides, become fully solvated, losing the supramolecular order depicted in Figure 5 and the relevant properties, especially in highly diluted mixtures $[50,51]$.

DESs exhibit similar properties to ILs, since they have a low vapour pressure and low melting point and are chemically and thermally stable, non-flammable and highly dissoluble. In addition, DESs are cheaper than ILs, water neutral, low or nontoxic and often biodegradable. DESs can be obtained from natural and/or readily available compounds in a simple way.

Particularly interesting for their low cost and biodegradability, DESs have unique properties for interacting with HBDs, such as renewable polyols or carboxylic acids [52]. When HBDs and HBAs are primary metabolites, such as aminoacids, organic acids, sugars 
or choline derivatives, the DESs are also called natural deep eutectic solvents (NADESs) [53]. NADESs fully address green chemistry principles: as opposed to organic solvents and ILs, the biodegradability of NADESs helps to avoid potential environmental hazards.

\section{Use of DES for the Treatment of Lignocellulosic Biomass}

The primary use of DESs for the valorisation of lignocellulosic biomass is based on the relevant capability of operating an effective separation of components. The intrinsic ionic nature produces the breaking of the supramolecular $\mathrm{H}$-bond, which stabilizes the hemicellulose-lignin complex in lignocellulosic biomasses, allowing the covalent bond to be broken more easily. In this way, the different components can also be reorganized under very mild conditions without generating possible inhibitors to the following depolymerization of cellulose to produce glucose [54]. DES pretreatment has been frequently used to fractionate the biomass [55,56], especially to solubilize and remove the lignin [57], leaving a residual cellulose-rich substrate more prone to be hydrolysed via enzymatic action than the starting lignocellulosic biomass [58] (Figure 7). This biomass fractionation approach with the DES is mainly focused on removing lignin from cellulose. However, hemicellulose plays a fundamental role in the purpose of valorising the initial biomass. As an easily hydrolysable polymer made up of C5 (mainly) and C6 sugars, it can be chemically exploited by separating it from the other biomass components, such as hydrolysed sugars. The quantitative solubilization of the hemicellulosic fraction will allow xylans to be recovered together with lignin for final conversion into other compounds with a high value (e.g., furfural [59]).

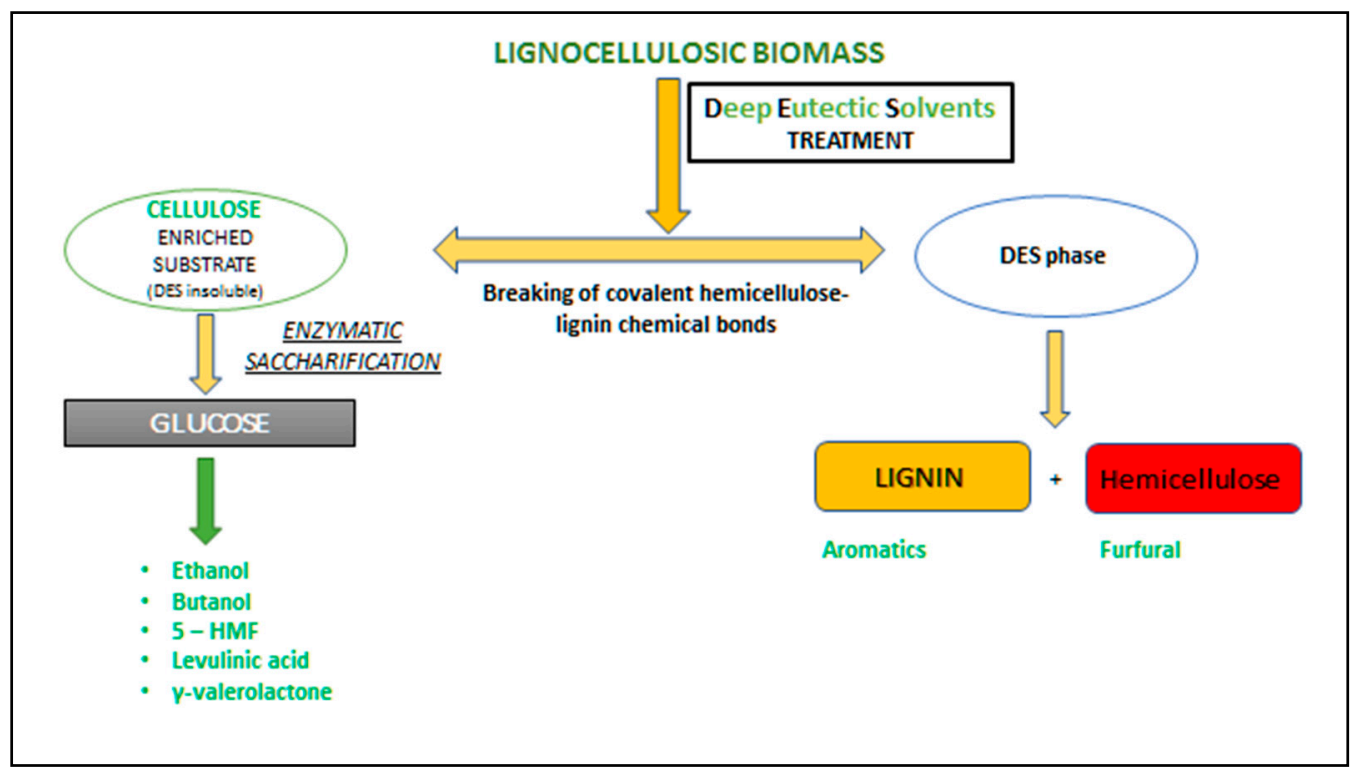

Figure 7. General scheme of the use of DES for lignocellulosic fractionation.

The number of published works on biomass pretreatment with DES systems has been steadily increasing since 2014, as shown in Figure 8. 


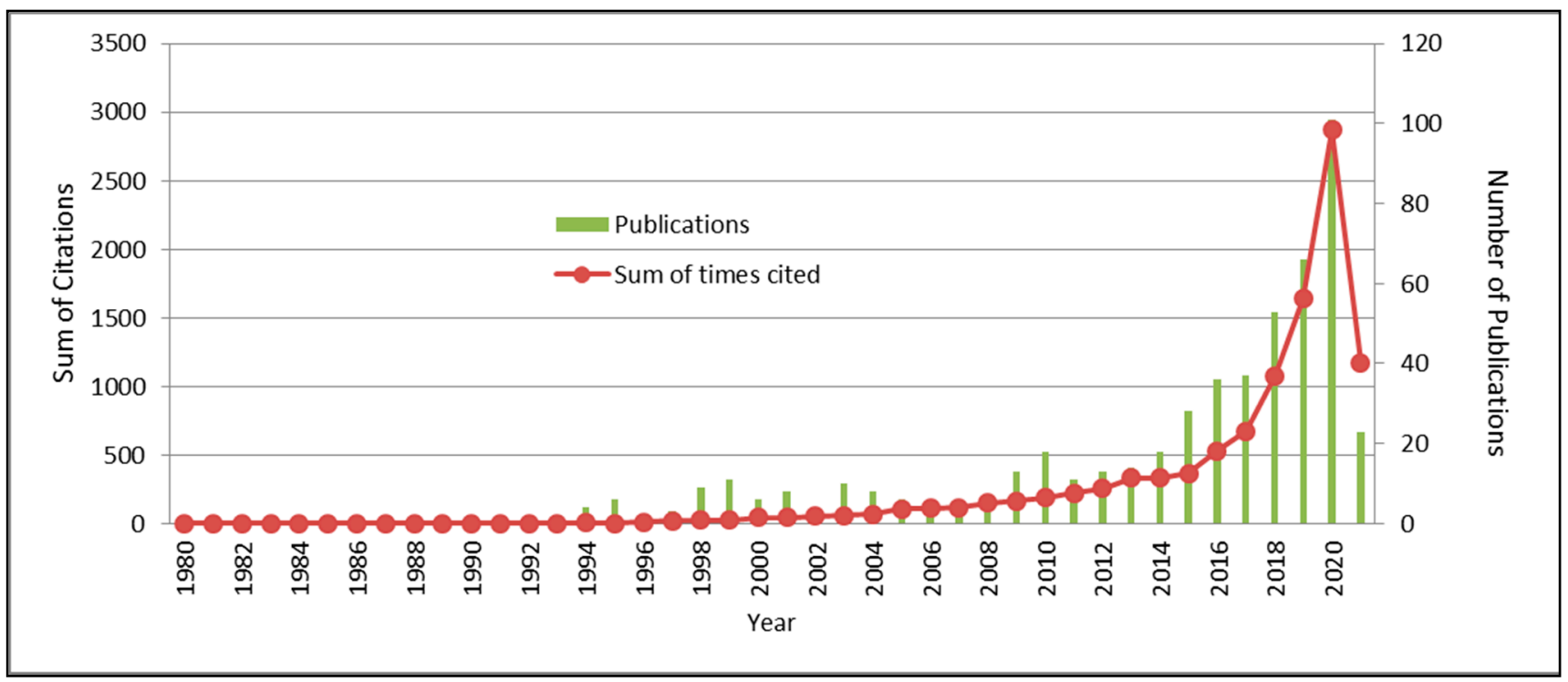

Figure 8. Analysis of recent literature available on "DESs Biomass" via "Web of Science": number of publications per year and sum of citations.

Most of these works dealt with binary DESs, simply composed of a combination of HBD and HBA. In Table 2 is reported a list of examples of DES treatments.

As stated above, the pretreatment of lignocellulosic biomass with DESs is usually finalised to solubilize lignin and hemicellulose, leaving the cellulose intact. The comparison of pretreatment operated by using different DESs is complicated due to the large number and complexity of the biomasses studied, which can interact in another way with the same type of DES. However, three experimental parameters, such as delignification yields, hemicellulose solubilization and cellulose recovery, can be considered to evaluate and compare the efficacy of a DES treatment. The main reactions involved during DES pretreatment of lignin are dehydration, depolymerisation, repolymerization, acylation and demethoxylation (Figure 9). 
Table 2. List of DES treatments.

\section{DES}

ChCl:ethylene glycol 2:1

ChCl:glycerol 1:1

ChCl:xylitol 1:1

ChCl: Oxalic/Malonic/Succinic/Malic/L-Tartaric Acid 2:1

Betaine:Lactic acid 2:1

ChCl-Lactic acid 1:10

Tri-ethylbenzyl ammonium chloride

(TEBAC)-LacticaAcid 1:7

$\mathrm{ChCl} —$ oxalic acid dihydrate 1:1

ChCl—urea/ethylene glycol/glycerol/lactic acid 1:2 $\mathrm{ChCl}$-oxalic acid 1:1

$\mathrm{ChCl}$ :formic acid 1:2 ChCl:acetic acid $1: 2$

ChCl:propionic acid 1:2

ChCl:lactic acid 1:2

ChCl:citric acid 1:1

ChCl:malic acid 1:1

ChCl:olycerol 1:2

ChCl:ethylene glycol 1:2

ChCl:diethylene glycol 1:2

ChCl:triethylene glycol 1:2

ChCl:xylitol 1:1

ChCl:urea 1:2

ChCl:formamide $1: 2$

ChCl:acetamide 1:2

ChCl:lactic acid:formic acid 1:1:1

ChCl:formic acidethylene glycol 1:0.4:1.6

ChCl:acetic acid:ethylene glycol 1:0.4:1.6

$\mathrm{ChCl}$ :propionic acid:ethyleneglycol 1:0.4:1.6

ChCl:lactic acid:ethylene glycol 1:0.4:1.6

ChCl:formic acid:ethylene glycol 1:1.2:0.8

ChCl:acetic acid:ethylene glycol 1:1.2:0.8

ChCl:propionic acid:ethyleneglycol 1:1.2:0.8

ChCl:lactic acid:ethylene glycol 1:1.2:0.8

Biomass/Conditions

Results

Rice straw $/ 80-150^{\circ} \mathrm{C}, 3-24 \mathrm{~h}$

biomass/DES ratio $5 \%$ wt

Moso Bamboo $/ 160^{\circ} \mathrm{C}, 10 \mathrm{~min}, \mathrm{MW}$ power $600 \mathrm{~W}$

Moso Bamboo $/ 200{ }^{\circ} \mathrm{C}, 10 \mathrm{~min}$

$100-140{ }^{\circ} \mathrm{C}, 6 \mathrm{~h}$

Corn Stover $/ 80-140{ }^{\circ} \mathrm{C}$ for $90 \mathrm{~min}$

Tender coconut husks and tamarind seeds $/ 90^{\circ} \mathrm{C}$ for $4 \mathrm{~h} ; 1: 15$ solid to liquid ratio

Bagasse $/ 100^{\circ} \mathrm{C}, 4 \mathrm{~h}$

Pine wood $/ 130^{\circ} \mathrm{C}$ for $6 \mathrm{~h}$
ChCl-Gly removed 74 wt. \% lignin with $91 \%$ glucan retention. Residual ChCl-Glycerol limited cellulase enzyme activity to $68 \%$. Sodium carbonate wash removed the residual DES, increasing the glucan digestibility to $87 \%$.

MW-DESs pretreatments reduced xylans content. Lignin still remains with $40 \%$ of removal. Enzymatic hydrolysis of pretreated samples produced $60 \%$ of glucans.

Total of $98.2 \mathrm{wt}$. \% hemicelluloses degraded and mainly converted into pentose.

Delignification reached $80.1 \%$ at $140{ }^{\circ} \mathrm{C}$; highly purified lignin $(99.49 \%$ ) was achieved

Glucan contents in pretreated CS were significantly increased from 30.99 to $67.07 \%$ with increasing temperature from 80 to $140^{\circ} \mathrm{C}$. Xylan contents decreased from 18.86 to $4.66^{\circ}$. Lignin contents decreased from 22.97 to $9.47 \%$. At $120^{\circ} \mathrm{C}$ the glucan recovery reached $77.43 \%$, respectively.

Cellulose recovery of $87.5 \%$ (92.3\% pure). DES was successfully reused with negligible effect on the delignification efficiency.

Up to $47.85 \%$ lignin was solubilized (oxalic acid). Minimum solubility of $8.60 \%$ is exhibited by the ethylene glycol DES. Acidic DES improved the crystallinity of bagasse fibre, whereas basic DES had little effect on the crystallinity of cellulose. after $\mathrm{ChCl} /$ lactic acid system treatment at $140^{\circ} \mathrm{C}$.

Acid DESs were the most efficient to solubilize hemicellulose and lignin, resulting in a glucan content increased. The lignin could be successfully isolated with high yield and high purity. DES could also be successfully recovered and reused without loss of performance. 
Table 2. Cont.

ChCl:glycerol 1:1; 1:2; 2:1 ChCl:urea $1: 1: 1: 2 ; 2: 1$ ChCl:glycerol:AlCl3.6H2O 1:2:0.2 ChCl:glycerol: $\mathrm{FeCl} 3 \cdot 6 \mathrm{H} 2 \mathrm{O}$ 1:2:0.2 ChCl:glycerol: $\mathrm{CrCl} 3 \cdot 6 \mathrm{H} 2 \mathrm{O}$ 1:2:0.2 ChCl:Urea 1:2 ChCl:Glycerol 1:2 ChCl:Malonic acid 1:1 ChCl:Formic acid 1:2 ChCl:Ethylene glycol 1:2 ChCl:1,4-butanediol 1:4 ChCl:Citric acid 1:1 $\mathrm{ChCl}$ Oxalic acid 1:1

Acetamide:Levulinic acid 1:2

ChCl:Levulinic acid 1:2

ChCl:lactic acid 1:10

ChCl:lactic acid 1:9

ChCl:lactic acid 1:5

ChCl:Glycerol:Lewis acid 62:124:1 (Ternary DES) Lewis acid: $\mathrm{AlCl}_{3} \cdot 6 \mathrm{H}_{2} \mathrm{O}, \mathrm{FeCl}_{3} \cdot 6 \mathrm{H}_{2} \mathrm{O}, \mathrm{FeCl}_{2} \cdot 4 \mathrm{H}_{2} \mathrm{O}$, $\mathrm{ZnCl}_{2}, \mathrm{CuCl}_{2}$

ChCl:Formic acid/Acetic acid/lactic acid 1:2

ChCl:Ethylene Glycol 2:1

ChCl:lactic/malic/citric/formic/acetic/ propionic/butyric/succinic/maleic acid Various molar ratio combinations at 2:1, 1:1, 1:2, 1:5, $1: 10$ and $1: 15$

ChCl:lactic acid 1:5

(+)-glucose:lactic acid 1:5

ChCl:D(+)-glucose 1:

ChCl:glycerol 1:2

$\mathrm{K}_{2} \mathrm{CO}_{3}$ :glycerol 1:6
Garlic skin Green onion

root/Biomass-DES 1:10 w/w; $110{ }^{\circ} \mathrm{C}$ $4 \mathrm{~h}$ (oil bath) $80^{\circ} \mathrm{C}, 20 \mathrm{~min}(\mathrm{MW})$ temperature

Corn stover $/ 80-120^{\circ} \mathrm{C}, 24 \mathrm{~h}$ followed by hydrolysis promoted by the carbon-based solid acid catalyst.

Moso Bamboo $/ 120^{\circ} \mathrm{C}, 2 \mathrm{~h}$

Eucalyptus Camaldulensis $/ 90-130^{\circ} \mathrm{C}$ $6 \mathrm{~h}$

Poplar wood meal $/ 120^{\circ} \mathrm{C}, 6 \mathrm{~h}$

Sugarcane bagasse $/ 80^{\circ} \mathrm{C}, 12 \mathrm{~h}$

Pennisetum/Biomass-DES 1:10 $w / w$

$$
60-140{ }^{\circ} \mathrm{C}, 1-9 \mathrm{~h}
$$

Hardwood poplar/Two-step process: Liquid Hot Water Extraction $\left(170^{\circ} \mathrm{C}\right.$ for $40 \mathrm{~min})$-DES treatment $\left(130^{\circ} \mathrm{C}\right.$ fo $3 \mathrm{~h}$; biomass-DES 1:20 w/w)

Eucalyptus globulus wood/Two-step pretreatment: hydrothermal treatmen

$$
170{ }^{\circ} \mathrm{C}, 4 \mathrm{~h}+90{ }^{\circ} \mathrm{C}, 24 \mathrm{~h} \text { (DES) }
$$

Oil palm empty fruit

bunch/Biomass/DES ratio 1:10 wt. $120^{\circ} \mathrm{C}, 8 \mathrm{~h}$

Oil palm empty fruit bunch/Biomass/DES ratio 1:10 wt. $120^{\circ} \mathrm{C}, 8 \mathrm{~h}$
The study demonstrated the effects of ultrasound frequency, the molar ratio, metal chloride, composition of DES at different heating methods on the components of biomass.

Total of $33.9 \%$ of xylose and $6.9 \%$ of glucose was recovered from $\mathrm{ChCl}$ :formic acid. The comparison between hydrolysis conducted in two steps, after pretreatment with DES (or

ILs), and the one-pot method showed that the glucose yield obtained by one-pot hydrolysis was much lower than the other.

ChCl:Levulinic acid presented 79.07\% glucose conversion yield, Acetamide:Levulinic acid $56.44 \%$ and Betaine:Levulinic acid $48.90 \%$.

Up to $80 \%$ lignin was removed and more than $44 \%$ could be collected. The enzymatic saccharification yields of cellulose was higher than $90 \%$.

Lignins were efficiently removed ( $95 \%$ ). The purity of regenerated lignin is very high (up to $98.1 \%$

Delignification $50.6 \%$

Enzymatic conversion $90.4 \%$

The use of Lewis acids significantly improved the delignification of Pennisetum, reaching $85 \%$ efficiency.

After the physical pretreatment, a solid yield of $79.8 \%$ and hemicellulose removal of $54.4 \%$ were observed. Cellulose content was increased from 61.1 to $79.8-85.4 \%$, corresponding to a relatively high extent of delignification of $73.0-76.5 \%$ after acidic DESs pretreatment.

The removal of lignin and hemicellulose was $90.2 \%$ and $97.4 \%$. Cellulose was effectively retained $(94.5 \%$ of the original cellulose content).

Formic acid (61.9\% lignin yield) and lactic acid (33.5\% lignin yield)-based DESs emerged for the highest lignin extraction yield.

Delignification:

ChCl:lactic acid $88 \%$

(+)-glucoselo

ChCl:glycerol $22 \%$

ChCl:urea $34 \%$

$\mathrm{K}_{2} \mathrm{CO}_{3}$ :glycerol $51 \%$

The acidic DES pretreatment allows the destruction of the hemicellulose: after the lactic acid based-DES treatment, no residual hemicellulose was detected in the solid. 
Table 2. Cont.

\section{DES}

ChCl:Monoethanol amine/N-methyldiethanolamine/ Urea/Acetamide/Diethanolamine/Glycero

Molar ratios 1:6,1:8,1:10,1:2,1:2 and 1:2

Guanidine $\cdot \mathrm{HCl}:$ Lactic acid

ChCl-Ethylene glyco

ChCl-Glycero

ChCl- Formamide

$$
\text { ChCl-Urea }
$$

ChCl-Guanidine $\cdot \mathrm{HC}$

ChCl-1,2-Propanedio

ChCl-1,3-Propanedio

ChCl-Glycolic acid

ChCl-Lactic acid

ChCl-2-Chloropropionic acid

ChCl-Oxalic acid

ChCl-Malonic acid

Molar ratio 1:1

ChCl:Lactic acid 1:10

Lactic acid/tartaric acid/ChCl 4:1:1

ChCl:oxalic acid 1:1

Cosolvents: butanol, $n$-propanol and ethyl acetate

[DES/cosolvent ratio 1:2, 1:1, 2:1]

ChCl:oxalic acid 2:1, 1:1 and 1:10

Cosolvent: MIBK

ChCl:Lactic acid 1:10

ChCl:Glycerol:Lewis acid $\left(\mathrm{AlCl}_{3} \cdot 6 \mathrm{H}_{2} \mathrm{O}, \mathrm{FeCl}_{3} \cdot 6 \mathrm{H}_{2} \mathrm{O}\right.$,

$\mathrm{CrCl}_{3} \cdot 6 \mathrm{H}_{2} \mathrm{O}, \mathrm{MgCl}_{2} \cdot 6 \mathrm{H}_{2} \mathrm{O}$

molar ratio $=1: 1: 0.3$

$\mathrm{ChCl}$ :acetic acid 1:2

ChCl:lactic acid 1:2

ChCl:levulinic acid 1.2

ChCl:glycerol 1:2

ChCl:p-hydroxybenzoic acid 3:2

ChCl:p-coumaric acid 1:1

$\mathrm{ChCl}$ :4-hydroxybenzylaldehyde 1.2

Biomass/Conditions

Results

Ref.

Wheat straw/Biomass/DES ratio $1: 20$ wt. $50-130{ }^{\circ} \mathrm{C}, 1-24$

ChCl-MonoethanolAmine is capable of removing 71.4\% lignin while reserving 93.7\% cellulose; $89.8 \%$ and $62.0 \%$ of cellulose and xylan conversions were eventually achieved through enzymatic hydrolysis of residue.
Rice straw/Biomass/DES 5 wt $\%$ $80{ }^{\circ} \mathrm{C}, 6 \mathrm{~h}$ or $120{ }^{\circ} \mathrm{C}, 3-6 \mathrm{~h}$
The pretreatment efficiency of the Lactic acid amide DES varied as the HBD structures changed and the pretreatment efficiency of these DESs displayed a similar trend as the polyol-based DESs.
Eucalyptus Camaldulensis $/ 60-140{ }^{\circ} \mathrm{C}$

Pinus pinaster $/ 175^{\circ} \mathrm{C}, 1 \mathrm{~h}$

Rice husk, rice straw $/ 50-80-120^{\circ} \mathrm{C} 1 \mathrm{~h}$ and wheat straw

Eucalyptus urophydis/Biomass/DES ratio 1:10 wt. MIBK/DES ratio $1.6 w / w$ $100-160^{\circ} \mathrm{C}, 30-120 \mathrm{~min}$

Pinus bungeana Zucc./Biomass/DES ratio $6.25 \% w t$

$120^{\circ} \mathrm{C}, 4 \mathrm{~h}$ (oil bath) $120^{\circ} \mathrm{C}, 8 \mathrm{~min}$ MW, $800 \mathrm{~W}$ ).

Sugarcane Bagasse/Pretreatment with

ethanol ultrasound at various ultrasonic frequency.

Biomass/DES ratio 1:10 wt. $100-140{ }^{\circ} \mathrm{C}, 1-4 \mathrm{~h}$ Poplar wood

Douglas fir $/ 90-180{ }^{\circ} \mathrm{C}$ $1-9 \mathrm{~h}$

Poplar wood/Biomass/DES ratio 1:10 wt. $100-160{ }^{\circ} \mathrm{C}$ for $1-9 \mathrm{~h}$
The DES pretreatment temperatures influence the cleavage of $\mathrm{C}-\mathrm{O}$ and $\mathrm{C}-\mathrm{C}$ bonds in the lignin dehydration, and acylation of $\mathrm{OH}$ groups and partial recondensation were observed.

Lactic acid: $\mathrm{ChCl}$ extracted the highest lignin amount, while the purest lignin was achieved with Tartaric Acid:ChCl. With the ternary DES, it registered a recovery of ca. $95 \%$ of lignin present in the biomass with a purity of ca. $89 \%$.

Delignification using the ternary combination system (DES-n-butanol) was at least $50 \%$ higher than that of pure DES treatment (23-31\% delignification)

At $140{ }^{\circ} \mathrm{C}$ for $90 \mathrm{~min}$, the maximum yield of Furfural was $70.3 \%$, and the maximum saccharification was $80.8 \%$.

The cellulose conversion of biomass pretreated with MW-DES achieved 81.9\%. DES pretreated samples $(41.6 \%)$

The sequential multifrequency ultrasonic and DES (with Lewis acid) pretreatment enhanced the delignification of lignin and cellulose recovery from biomass.

Delignification: 78\% from poplar and 58\% from D. fir. Highly pure lignin (95\%) with unique structural properties was recovered.

$\mathrm{ChCl}$ - p-hydroxybenzoic acid showed the best performance in terms of delignification $(69 \%)$ and digestibility of glucan and xylan $(90.8 \%$ and $88.9 \%)$ 


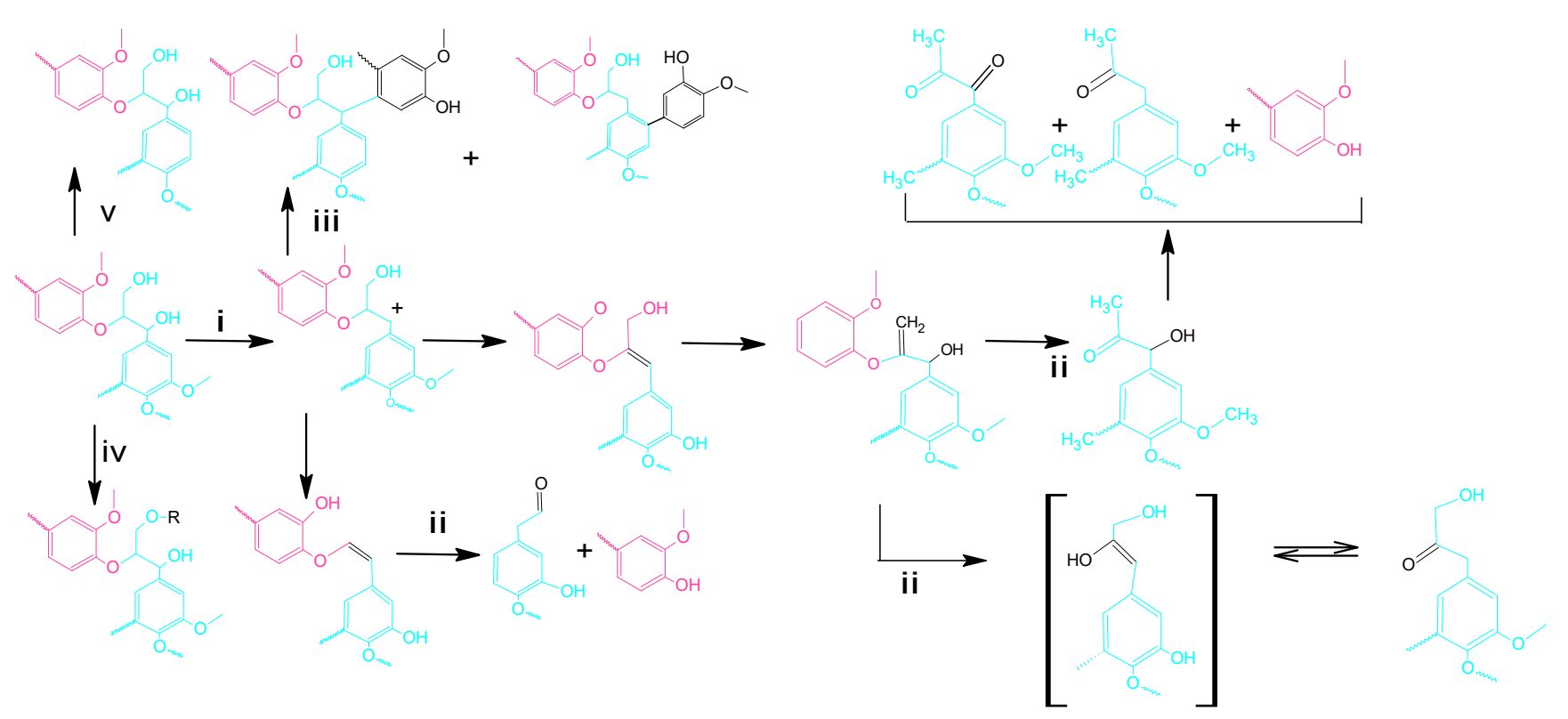

Figure 9. Lignin reactions during DES pretreatment: (i) dehydration, (ii) depolymerization, (iii) repolymerization, (iv) acylation and (v) demethoxylation.

In general, the best performances are recorded by using acid DESs: for example, those synthesized starting from $\mathrm{ChCl}$ and lactic acid, which reach near $90 \%$ delignification yield and complete solubilization of the hemicellulose $[65,66,68]$. Neutral DESs do not achieve comparable performance. Amine- and amide-based DESs are less investigated as compared to poly-alcohol- and acid-based DESs. As reported in the literature, lignin is soluble in an alkaline medium, and this can be exploited to remove lignin from raw biomass, breaking the ether linkages in lignin and ester linkages between lignin and hemicellulose, and thus favouring the consequent enzymatic degradation of cellulose. The removal of lignin and xylan by $\mathrm{ChCl}$ :Urea from different biomass sources (rice, straw and oil palm empty fruit bunch) was, respectively, around 30\% and 20\% [46,80]. Zhao et al. evaluated the wheat straw fractionation efficiency of various alcohol-amine- (monoethanolamine, diethanolamine and methyldiethanolamine) and amide-based (acetamide and urea) DESs. Compared to DESs based on urea and acetamide, the DESs based on amines show better performances for biomass fractionation. This behaviour can be linked to the high basicity nature of the HBD component. The amide-based DESs ( $\mathrm{pH}$ 7.3-8.2) show worse performances than alcohol-amine-based DESs ( $\mathrm{pH} 10.4-10.9$ ). A total of 81\% and $47 \%$ of lignin and xylan, respectively, was removed when straws were pretreated with monoethanolamine-based DESs [48]. The high delignification yields recorded for basic DESs are attributable to forming strong hydrogen bonds with the phenolic groups present in the lignin. The cellulose and xylan conversions are only $20.9 \%$ and $8.9 \%$ for untreated wheat straw and enormously improved after monoethanolamine-DES pretreatment to $92.4 \%$ and $75.8 \%$, respectively.

An interesting study was published by Oh et al. [62], which investigated the delignification performance on pine wood of $25 \mathrm{ChCl}$-based DESs with different chemical-physical characteristics. Acid HBDs were the most effective at dissolving hemicellulose and lignin. DES-mediated pretreatment of biomass increased the glucan content, whereas hemicellulose and lignin were efficiently removed. The results obtained show a correlation between the polarity and the acidic nature of DES and its efficacy in the extraction of lignin and hemicellulose from biomass [81]. Tan et al. investigated the role of the $\mathrm{pH}$ of the HBD component of the DES system, synthesizing three different classes of DESs for the pretreatment of lignocellulosic oil palm empty fruit bunch: Acidic (ChCl-lactic acid); Near 
Neutral (ChCl: D-(+)-glucose 1:1, ChCl:glycerol 1:2); and Basic (ChCl:urea 1:2, potassium carbonate:glycerol 1:6 molar ratio). DES systems with acidic and basic $\mathrm{pH}$ were able to solubilize biomass components better than DES with $\mathrm{pH}$ around neutrality.

A multivariate analysis of parameters demonstrated that the hydrophilic ability, polarity, acidity and capability to form hydrogen bonds of HBDs were the most influencing properties associated with DESs for the delignification yields. The three variables that had the most critical impact were, in order of priority: (1) oil-water partition coefficient $(\log \mathrm{P}),(2)$ acidity coefficient $(\mathrm{pKa})$ and (3) the number of hydrogen bond donors of HBD. In contrast, the three operative variables that had the most crucial impact on the pretreatment of biomass were the temperature (T-R), the severity factor of reaction ( $\mathrm{R}$ factor) and the ratio of HBD to HBA (DES ratio), respectively [82]. As mentioned above, the fractionation of lignocellulosic biomass occurs via a combined action of the displacement of the initial H-bond, which confers the supramolecular interactions in the lignocellulose, with new ones with the DES's components and the breaking of covalent bonds of the LCC (Figure 3). In any case, the pretreatment with DES may be too harsh to be selective at the point of further realizing a reaction on the typical bonds of lignin.

In general, neutral DESs are able to recover lignin without affecting the initial complexity of LCC structures. On the contrary, acid or alkaline DESs produce larger lignindissolution with shortening of the fragment solubilized.

The kraft lignin solubility was enhanced by increasing either the HBD's carbon chain length or the molar ratio, with $\mathrm{ChCl}$ 1,6-hexanediol and $\mathrm{ChCl}$ :maleic acid being the best DESs for kraft lignin dissolution. At the same time, the addition of water was a negative factor. Thermal treatments $\left(120^{\circ} \mathrm{C}\right)$ with carboxylic acid-based DESs produce chemical modifications to kraft lignin, including the breaking of several $\mathrm{C}-\mathrm{O}$ covalent bonds (namely $\beta-\mathrm{O}-4, \alpha-\mathrm{O}-4$ and $\alpha-\mathrm{O}-\alpha)$ [51].

The preservation of alkyl-aryl ether bonds in extracted lignin would favour lignin depolymerization and maximize its valorisation potential for platform and speciality chemicals, especially aromatics. However, fractioning lignin from lignocellulosic biomass breaks down not only glycosidic side chains but also phenolic alkyl-aryl ether bonds (e.g., $\beta-\mathrm{O}-4)$. Acidified $\mathrm{ChCl}$ :Ethylene Glycol was highly effective for lignin and hemicellulose dissolution while preserving most cellulose during switchgrass fractionation [83].

Lignin properties, including molecular weight, an abundance of ether bonds, condensation extent and thermal stability, were tuneable by controlling the pretreatment conditions and DES compositions (e.g., water content, the molar ratio of HBA and HBD).

The use of ChCl-lactic acid and $\mathrm{ChCl}$-oxalic acid at $80-120{ }^{\circ} \mathrm{C}$ for $6 \mathrm{~h}$ promoted the disruption of a large number of ether bonds (especially $\beta-\mathrm{O}-4^{\prime}$ linkages (Figure 2)), leading to an increased number of phenolic $\mathrm{OH}$ groups and lower molecular weights. The $\mathrm{ChCl}$-lactic acid pretreatment, in addition to $\gamma$-acetylated groups, also produces phenolic diketones in lignin. Based on the comprehensive analysis, the mechanism of the cleavage of $\beta-\mathrm{O}-4^{\prime}$ bonds during DES pretreatment could have two feasible routes: the removal of $\mathrm{C} \alpha \mathrm{OH}$ groups to form benzylic carbocations and the oxidation of $\mathrm{OH}$ groups to obtain $\mathrm{C} \alpha$ ketones [84].

DES pretreatment with increasing ChCl:lactic acid ratio improved the enzymatic digestibility of bamboo residues effectively. When bamboo was pretreated with $\mathrm{ChCl} /$ lactic acid $1: 4$ at $130{ }^{\circ} \mathrm{C}$, the best enzymatic hydrolysis yield could be obtained $(76.9 \%)$. The improvement of the enzymatic digestibility of cellulose was positively correlated with improved accessibility [85].

ChCl:formic acid could increase cellulose accessibility by removal of hemicellulose and lignin, leading to a high crystallinity index. In butanol fermentation, using DES pretreated hydrolysates by Clostridium saccharobutylicum DSM 13864, a butanol yield of $0.17 \mathrm{~g} \mathrm{~g}^{-1}$ of total sugar was attained without an apparent inhibitory effect [86].

$\mathrm{ChCl} / \mathrm{p}-\mathrm{TsOH}$ treatment coupled with $\mathrm{NaOH}$ post-treatment was effective for poplar residues and herbaceous miscanthus valorisation. A near-complete enzymatic hydrolysis 
yield could be achieved: per $1.5 \mathrm{~kg}$ dried biomass, $648.0 \mathrm{~g}$ (poplar) and $637.7 \mathrm{~g}$ (Miscanthus) glucose could be obtained [87].

A glucose yield of $75.8 \%$ was also attained at $130{ }^{\circ} \mathrm{C}$ with a $\mathrm{ChCl} /$ lactic acid molar ratio of 1:2, with a lignin recovery from the DES phase of $48.6 \%$. The isolated lignin presented $S$ and $G$ units not condensed, a low abundance of $\beta-O-4$ linkages, high purity, homogenous distribution and a large diffusion of phenolic $\mathrm{OH}$-groups [88].

The influence of the chemical structure of acid HBD was also studied: the alphahydroxy monocarboxylic acid-based DES group produced a higher lignin extraction yield than di- and tricarboxylic acid, evidence that finds confirmation in Hou's work [72]. Different acidic groups in malic and citric acid can form extensive chains of the dimer, which reduce the mobility of solvent molecules, which turns out to be more viscous and does not promote lignin extraction. The linear saturated acid group shows the worst lignin extraction yield compared with all the monocarboxylic acids used. The elongation of the alkyl chain leads to a decrease in extraction yield. These results suggest that additional functional groups in acid HBD significantly affected the lignin dissolution ability of DES. The short alkyl chain, hydroxyl group and unsaturation in acid HBD improved the DES performance. On the contrary, the presence of more than one carboxylic acid group weakened the DES performance.

\subsection{New DES-Based Combined Pretreatment Strategies}

In the last few years, the use of DES systems in the valorisation of lignocellulosic biomass evolved into new more complex systems. Ternary systems or the combined use of binary DES with other chemical compounds (e.g., alcohol, organic solvents) and catalysts (Lewis acids, etc.) or a combination with hydrothermal treatment, ultrasonic irradiation or microwave (MW) irradiation was beneficial in terms of efficiency.

\subsubsection{Ternary DES}

A clear example of the benefits achieved with the use of a ternary DES was recently investigated [74]: lactic acid, tartaric acid and $\mathrm{ChCl}$ in a molar ratio of 4:1:1 were tested on biomass maritime pine sawdust (Pinus pinaster Ait.). Some binary DESs were previously studied in the biomass pretreatment, and lactic acid, tartaric acid and $\mathrm{ChCl}$ have been identified as components of the ternary DES to be synthesized, because it was noticed that lactic acid: $\mathrm{ChCl}$ was capable of extracting the highest lignin amount, whereas the purest lignin was achieved with Tartaric Acid:ChCl. The prepared DES lactic acid:tartaric acid: $\mathrm{ChCl}$ is the most efficient of the DESs studied for selective lignin extraction and recovery. The operating parameters have been optimized and the temperature of $175{ }^{\circ} \mathrm{C}$ for $1 \mathrm{~h}$ allowed ca. $95 \%$ of the initial lignin present in pine sawdust to be recovered, with a ca. $89 \%$ purity.

A ternary DES composed of $\mathrm{ChClChCl}$, boric acid (BA) and polyethylene glycol-200 (PEG) was also used on wheat straw treatment. It could dissolve a large amount of lignin and hemicellulose (up to $88.39 \%$ and $84.38 \%$, respectively), with enzymatic digestibility of residual cellulose of $59.3 \%$. The lignin's removal rate was positively correlated with the amount of BA. Structural studies showed that the regenerated lignin is a typical $\mathrm{H}-\mathrm{G}-\mathrm{S}$ type, retaining its intact structure (e.g., $\beta-\mathrm{O}-4, \beta-\beta, \beta-5$, etc.). Density functional theory showed that BA could bond with $-\mathrm{OH}$ similar to $\mathrm{Cl}^{-}$, and it occupied more effective sites than $\mathrm{Cl}^{-}$, breaking the hydrogen-bonding network between lignin and cellulose. Importantly, the DES can be used multiple times without significantly reducing its efficiency, and its structure and properties remain virtually unchanged throughout [89].

\subsubsection{Alcohols and Organic Solvents}

The effects of the presence of alcohol as a cosolvent in a DES system on its delignification performance were studied by Kandaelli et al. [75]. They examined three different biomasses and a single DES system, consisting of $\mathrm{ChCl}$ and oxalic acid (1:1 molar ratio), to investigate the influence of alcohol (butanol, n-propanol and ethyl acetate) on the delig- 
nification process. These organic solvents were chosen for their high ability to solubilize lignin and for their miscibility in DES. Delignification using this novel ternary combination system was at least $50 \%$ higher than that of pure DES treatment. The reaction temperature and especially the ratio of DES-alcohol are critical for an effective biomass delignification: the maximum effectivity was obtained on the use of butanol as cosolvent and can be attributed to a higher fractionation of lignin and its minimal miscibility in water.

Another biphasic system formed by the acid DES ChCl-oxalic acid and the organic solvent MIBK was also investigated in the presence of $\mathrm{AlCl}_{3} \cdot 6 \mathrm{H}_{2} \mathrm{O}$ for the pretreatment of Eucalyptus urophydis biomass [90]. The pretreatment enhanced the enzymatic hydrolysis of the substrate: cellulose bundles were broken up, which benefited from converting cellulose into glucose by enzymatic hydrolysis. The biphasic system significantly improved the concomitant synthesis of Furfural (FF), compared to the single solvent system (DES or MIBK), which was due to the high solubility of lignocellulose in DES and the high solubility of Furfural in MIBK. FF is an important, renewable platform chemical from hemicelluloses, is considered to be one of the platform chemicals with the highest potential and can be used in many industrial fields. The yield of FF in the DES/MIBK biphasic system was much higher than that of the $\mathrm{AlCl}_{3}$-catalyzed hydrothermal pretreatment of Eucalyptus, in which the yield of FF was only $17.85 \%$ [91]. The optimum pretreatment conditions were $140{ }^{\circ} \mathrm{C}$ for $90 \mathrm{~min}$, the maximum yield of FF registered was $70.3 \%$ and the maximum saccharification was $80.8 \%$, which was much higher than that evaluated for the raw material.

The use of solvents is also beneficial when adopted after the first step of the biomass treatment with a DES reagent $(\mathrm{ChCl} /$ lactic acid at a 1:2 molar ratio) in liquid-liquid extraction. The $\mathrm{THF} / 25 \%$ aq $\mathrm{NaCl}$ combination greatly assisted in attaining a higher extraction of lignin ( $>88 \%$ relative lignin yield) through a biphasic separation and made the setup facile ( $>95 \%$ solvent recovery for reuse) [92].

The combination of 2-aminoethanol, tetra-n-butyl ammonium bromide and a cyclic ether (THF) was also positively proven to be effective for selective delignification of rice straw already at $100{ }^{\circ} \mathrm{C}$. The treatment with this combination of DES-THF solvent system produced $\sim 46 \%$ delignification. The recovery of cellulose $(\sim 91 \%)$ and hemicellulose $(\sim 67 \%)$ was high. The new solvent system could be reused for up to 10 subsequent cycles with the same effectivity [93].

\subsubsection{Lewis Acids}

The pretreatment of Pennisetum biomass, performed with a neutral DES (ChCl:glycerol), was also positively tested in the presence of different Lewis acids as metal chlorides [94,95]. Glycerol-based DESs were not effective for biomass fractionation, as reported in several published studies: the recovery of lignin was contained, while the relevant structure was only slightly modified $[79,96,97]$. Previous studies have also shown that the presence of a Lewis acid in an aqueous/alcoholic media can facilitate the dissolution of hemicellulose and, therefore, can synergistically improve the effectiveness of pretreatment with DES $[96,97]$. Such behaviour can be imputed to the coordinating capability of these systems with water/alcohol molecules, becoming, in fact, a Brønsted acid with a strength comparable to mineral acids [98-101]. $\mathrm{AlCl}_{3}, \mathrm{FeCl}_{3}$ and $\mathrm{CuCl}_{2}$ significantly improved the delignification of Pennisetum, achieving $85 \%$ efficiency. This high reactivity may be due to the enhanced acidity and the new DES structure after incorporating the catalyst to produce a DES of Type I (see the classification reported above). The combination of $\mathrm{FeCl}_{3}$ and $\mathrm{ChCl} /$ glycerol was effective and recyclable. As compared to the DES with $\mathrm{FeCl}_{2}, \mathrm{ZnCl}_{2}$, $\mathrm{AlCl}_{3}$ and $\mathrm{CuCl}_{2}$, the DES with $\mathrm{FeCl}_{3}$ approvingly retained most of the cellulose in pretreated Hybrid Pennisetum (95.2\%). Meanwhile, the cellulose saccharification significantly increased to $99.5 \%$. The excellent pretreatment performance was mainly attributed to the high removal of lignin (78.88 wt. \%) and hemicelluloses (93.63 wt. \%) under the combined effect of Lewis acid and the proper hydrogen-bond interaction of $\mathrm{FeCl}_{3}$ with DES [102]. 


\subsubsection{DES Pretreatment Coupled with Ultrasonic Irradiation and MW}

The synergistic effect of ultrasonication with DES-based pretreatment was investigated on the oil palm empty fruit bunch [103]. Three different types of DESs, namely ChCl:lactic acid, ChCl:urea and ChCl:glycerol, were studied. The highest yield of reducing sugars $(36.7 \%)$ under the action of ultrasonication for $15 \mathrm{~min}$ at a sonication power of $210 \mathrm{~W}$ and temperature $50{ }^{\circ} \mathrm{C}$ was detected for the DES based on lactic acid. Furthermore, the pretreated biomass showed a significant change in structure and morphology, associated with the lowest crystallinity and lignin content.

The coupling between a preliminary ultrasound irradiation step [77] and the treatment with a ternary DES (ChCl:glycerol:Lewis acid) improved the biomass sugarcane bagasse delignification and saccharification yields [78]. Compared to the raw biomass, cellulose content increased, while the lignin and hemicellulose contents decreased after ultrasound pretreatment. Ultrasonic cavitation affects the structure of sugarcane bagasse, degrading the complex matrix, reducing the particle size and increasing the surface area of biomass, enhancing the accessibility to chemical attacks of biomass.

$\mathrm{ChCl} /$ oxalic acid dihydrate was also positively applied for wood lignocellulose fractionation. DES and MW irradiation had a powerful synergetic effect on cleaving the LCC structure and achieving an ultrafast fractionation of WL. The extracted lignin had a low molecular weight (913), low polydispersity (1.25) and high purity and could be used as feedstock for the production of aromatic chemicals. Glucose, xylose and HMF were also generated during the one-pot process. The undissolved residue contained cellulose with a crystal I structure, having a crystallinity of around $75 \%$ and a degree of polymerization of 285 units, becoming a potential precursor for the production of nanocellulose and/or bioethanol [56].

\section{Lignin Valorisation and Novel Hardwood Lignin-Based DES}

In recent years, more and more research groups have focused their attention on the enhancement of the lignin present in biomass of different origins, being one of the most abundant components. The prevalent aromatic nature of lignin makes it a possible source of low-molecular-weight aromatic chemicals $[59,75,76]$. Lignin valorisation as a source of simple aromatics is mainly influenced by the degrees of condensation, which can be measured by the number of cleaved $\beta-\mathrm{O}-4$ ether bonds and the $\mathrm{C}-\mathrm{C}$ bonds formed among the different interunits during biomass fractionation. As reported in various studies, DES systems allow the extraction of lignin from biomass with high yields (about $90 \%$ ) at $140{ }^{\circ} \mathrm{C}$ but are not able to overcome the problems of condensation and breaking of chemical bonds $[56,79,104]$. To hinder the cleavage of aryl ether and to preserve the original lignin structure by avoiding the condensation of interunits, Wang et al. [105] synthetized a novel DES formed by $\mathrm{ChCl}$ and $\mathrm{p}$-toluenesulfonic acid ( $\mathrm{p}-\mathrm{TsOH})$ as $\mathrm{HBD}$, and they tested this combination to fractionate wheat straw and miscanthus biomass. Lignin and hemicellulose were easily and quickly dissolved in a concentrated $\mathrm{p}-\mathrm{TsOH} / \mathrm{ChCl}$ solvent due to the similar polarity and the capability of generating weak secondary interactions (namely, hydrogen bonding and $\pi-\pi$ stacking). As usual, cellulose was hardly dissolved by $\mathrm{p}-\mathrm{TsOH} / \mathrm{ChCl}$. This specific DES also efficiently fractionated herbaceous biomass at atmospheric pressure and low temperatures $\left(75^{\circ} \mathrm{C}\right)$ : in a short time $(20 \mathrm{~min}), \mathrm{p}-\mathrm{TsOH} / \mathrm{ChCl}$ solubilized $76.6 \%$ and $88.9 \%$ of miscanthus and wheat straw lignin, respectively. In both cases, a $\beta-\mathrm{O}-4$ content of about $32 \%$ was preserved. Compared to $\mathrm{p}-\mathrm{TsOH} / \mathrm{H}_{2} \mathrm{O}$ fractionation, the treatment with DES allows for obtaining a lignin residue with a high content of bonds to the detriment of the delignification performance.

A new class of DESs synthesized from lignin-derived phenolic compounds has been receiving increasing attention: 4-hydroxybenzyl alcohol, catechol, vanillin and p-coumaric acid can be used as HBDs with $\mathrm{ChCl}$. These new DES were tested as solvents in the pretreatment of switchgrass. A total of $60.8 \%$ of lignin was solubilized, and the enzymatic digestibility of the residue was significantly increased (70\% glucan yield). Furthermore, they can be recovered and reused without any significant loss of pretreatment performance. 
p-hydroxybenzoic acid, p-coumaric acid and 4-hydroxybenzylaldehyde, which are phenolic units typically found in hardwood lignin, were also tested as HBDs with $\mathrm{ChCl}$ for an efficient poplar biomass conversion [41]. The best lignin and xylan removal performances were recorded for p-hydroxybenzoic acid with enzymatic digestion yields of around $90 \%$ for glucan and xylan.

\section{Use of DES in the Valorisation of Cellulose}

A high carbon content and the importance of its fundamental building unit (glucose) make cellulose suitable for synthesizing many chemical compounds, such as cellulosebased polymers; poly- and monosaccharides (fructose and glucose); sugar-derived platform molecules, such as HMF; and levulinic acid.

Cellulose conversion often needs particular treatment and severe operative conditions since the crystalline structure or the native state in the biomass prevents the easy conversion of such a compound. Strong acids, high temperatures and a considerable number of organic solvents are often used in technologies in which cellulose is the starting material.

In this section, the use of various DESs in several processes for the valorisation of cellulose is reviewed. The properties of DESs will be reported and discussed from three main perspectives, namely as a solvent, catalyst or active reagent in the synthesis of valuable products.

\subsection{DES as a Non-Derivatising Solvent for Cellulose}

The solubilization of cellulose is an unprecedented challenge for its effective processing into various end products. The supramolecular structure of cellulose obtained as a result of a hydrogen-bond between polyglucose chains makes this polysaccharide stable and sparingly soluble in most solvents. In addition, this structure is responsible for the resistance to biological and chemical conversion into valuable products [106,107]. In principle, cellulose dissolution is achieved upon hydrogen bond breaking. Solvents should destroy original inter- and intramolecular hydrogen bonds by generating new hydrogen bonds with the hydroxyl groups of the cellulose. In DESs, this replacement can occur through one or more components of the solvent systems and/or by coordination of the metal ion possibly present in the dissolving medium [108,109].

However, as Lindman suggested [110], the low solubility of cellulose in water reveals that hydrogen bonds are not the only ones responsible for the dissolution process: the hydrophobic interaction present in the supramolecular structure also gives a marked contribution so that species able to make this kind of interaction are also required in order to promote the solubility of cellulose.

Generally, solvents that overthrow this internal cohesion physically dissolve cellulose principally through intermolecular interactions [111,112]. Commonly used solvents that dissolve cellulose include aqueous metal complexes (namely, copper(II) ethylenediamine (Cuen)), aqueous bases $(10 \% \mathrm{NaOH})$, concentrated mineral acids (e.g., $\mathrm{H}_{2} \mathrm{SO}_{4}, \mathrm{H}_{3} \mathrm{PO}_{4}$ ), ILs (e.g., 1-ethyl-3-methylimidazolium acetate), molten salt hydrates (e.g., $\mathrm{ZnCl}_{2} \cdot 4 \mathrm{H}_{2} \mathrm{O}$ ), di-methyl acetamide/ $\mathrm{LiCl}$ solvents, DMSO-based solvents, $\mathrm{NH}_{3}$-based solvents (e.g., $\mathrm{NH}_{3} / \mathrm{NH}_{4} \mathrm{SCN}$ ), tertiary amine oxides (e.g., N-methyl-morpholine-N-oxide (NMMO)) and $\mathrm{LiOH} /$ urea solvents [113-115]. Among these, ILs resulted in being very interesting solvents: 21 ILs were screened for cellulose and wood chip dissolution by Zavrel et al., revealing that [emim]OAc was the most efficient for cellulose dissolution [115].

Recently, DESs with physicochemical properties similar to this IL have attracted considerable interest due to their lower cost, more straightforward synthesis process and higher biodegradability $[43,55,116,117]$. A list of DESs that are currently used as solvents for cellulose is reported in Table 3. 
Table 3. DESs for cellulose dissolution.

\begin{tabular}{|c|c|c|c|c|}
\hline Feedstock & DESs & Operative Conditions & S (wt. \%) & Ref. \\
\hline MCC & $\mathrm{ChCl} /$ urea & $\mathrm{T}=110^{\circ} \mathrm{C}, 12 \mathrm{~h}$ & $<0.2$ & [117] \\
\hline MCC & $\mathrm{ChCl} / \mathrm{ZnCl} 2$ & $\mathrm{~T}=110^{\circ} \mathrm{C}, 12 \mathrm{~h}$ & $<0.2$ & [117] \\
\hline MCC & {$[\mathrm{Ch}] \mathrm{OAc}$} & $\mathrm{T}=110^{\circ} \mathrm{C}, 12 \mathrm{~h}$ & 0.5 & [117] \\
\hline MCC & $\begin{array}{c}{[\mathrm{Ch}] \mathrm{OAc} /[\mathrm{TBMA}] \mathrm{Cl}} \\
(15 \text { wt. } \%)\end{array}$ & $\mathrm{T}=110^{\circ} \mathrm{C}, 10 \mathrm{~min}$ & 6 & [117] \\
\hline $\begin{array}{l}\text { Cotton linter pulp } \\
\quad(\mathrm{DP}=575.6)\end{array}$ & $\mathrm{ChCl} /$ urea & ultrasound activation; $\mathrm{T}=120^{\circ} \mathrm{C}$ & 1.43 & [118] \\
\hline $\begin{array}{l}\text { Cotton linter pulp } \\
\quad(\mathrm{DP}=575.6)\end{array}$ & $\mathrm{ChCl} /$ imidazole & ultrasound activation; $\mathrm{T}=120^{\circ} \mathrm{C}$ & 2.48 & [118] \\
\hline $\begin{array}{l}\text { Cotton linter pulp } \\
\quad(\mathrm{DP}=575.6)\end{array}$ & $\mathrm{ChCl} /$ imidazole & $\begin{array}{c}\text { ultrasound activation; } \mathrm{T}=120^{\circ} \mathrm{C} \\
\text { cosolvent }=5 \% \text { PEG }\end{array}$ & 4.57 & [118] \\
\hline $\begin{array}{l}\text { Commercial cellulose } \\
\text { (Merck) }\end{array}$ & $\mathrm{ChCl} /$ maleic acid & $\begin{array}{l}\text { ultrasound activation; } \mathrm{T}=90^{\circ} \mathrm{C} \text {, } \\
20 \mathrm{~min}\end{array}$ & 2.57 & [119] \\
\hline $\begin{array}{l}\text { Commercial cellulose } \\
\text { (Merck) }\end{array}$ & $\mathrm{ChCl} / \mathrm{a}-$ naphthol & $\begin{array}{l}\text { ultrasound activation; } \mathrm{T}=90^{\circ} \mathrm{C} \text {, } \\
20 \mathrm{~min}\end{array}$ & 3.39 & [119] \\
\hline $\begin{array}{l}\text { Commercial cellulose } \\
\text { (Merck) }\end{array}$ & $\mathrm{ChCl} /$ phenol & $\begin{array}{l}\text { ultrasound activation; } \mathrm{T}=90^{\circ} \mathrm{C}, \\
20 \mathrm{~min}\end{array}$ & 4.70 & [119] \\
\hline $\begin{array}{l}\text { Commercial cellulose } \\
\text { (Merck) }\end{array}$ & $\mathrm{ChCl} /$ resorcinol & $\begin{array}{l}\text { ultrasound activation; } \mathrm{T}=90^{\circ} \mathrm{C} \text {, } \\
\qquad 20 \mathrm{~min}\end{array}$ & 6.10 & [119] \\
\hline MCC & Glyn-EmimCl & $\mathrm{T}=100{ }^{\circ} \mathrm{C}, 3 \mathrm{~h}$ & 5 & [120] \\
\hline MCC & Glyn-EmimCl & $\mathrm{MW}, 6 \mathrm{~s}$ & 5 & [120] \\
\hline $\begin{array}{l}\text { Cotton linter pulp } \\
\quad(\mathrm{DP}=575.6)\end{array}$ & $\begin{array}{l}\text { Triethyl-allyl ammonia } \\
\text { chloride/oxalic acid }\end{array}$ & $\mathrm{T}=110{ }^{\circ} \mathrm{C}, 2 \mathrm{~h}$ & 6.48 & [121] \\
\hline
\end{tabular}

Chen et al. have recently reviewed the use of DESs as solvents for cellulose, underlining that, although positive results have been obtained up to now, several efforts are still required to reach satisfactory results [122]. The great advantage in the use of DESs is the possibility to tune the dissolution ability by modifying the selected DES constituents. A clear example was reported by Zhang et al.: they found that $\mathrm{ChCl} /$ urea (1:2) did not dissolve microcrystalline cellulose $\left(<0.2 \mathrm{wt}\right.$. \% solubility after $12 \mathrm{~h}$ at $\left.110^{\circ} \mathrm{C}\right)$, whereas the replacement of $\mathrm{Cl}^{-}$with $\mathrm{OAc}^{-}$and the addition of $15 \%$ tributylmethylammonium chloride yielded in the dissolution of $6 \mathrm{wt}$. \% of MCC in just $10 \mathrm{~min}$ at $110^{\circ} \mathrm{C}$ [117]. The obtained result gains more value if compared to [bmim] $\mathrm{Cl}$, a commonly used IL for cellulose activation that is capable of dissolving only $4 \mathrm{wt}$. \% of cellulose in $8 \mathrm{~h}$ at $130{ }^{\circ} \mathrm{C}$ [117]. After complete dissolution in [Ch]OAc/[TBMA]Cl, cellulose can be regenerated in an amorphous form after the addition of ethanol. DESs can be easily recycled without contaminating the regenerated cellulose, which is very attractive from the perspective of subsequent valorisation and conversion processes.

The solubility of cellulose could also be increased by using ultrasound-assisted pretreatment since the irradiation improves the penetration of solvents into cellulose and the mass transfer [123]. For instance, it was found that an ultrasound-assisted saturated $\mathrm{CaCl}_{2}$ solution increased the cellulose solubility up to $1.43 \mathrm{wt}$. \% in the presence of $\mathrm{ChCl}$ and urea (vs $<0.2 \%$ in the absence of ultrasound). When imidazole replaced the urea, the new DES solubilized more cellulose (2.48 wt. \%). The solubility could be further increased with the use of a cosolvent that reduced the hydrophobicity of cellulose, improving the accessibility of the solvent. In the presence of $5 \%$ of polyethylene glycol (PEG), the solubility of cellulose was doubled up to $4.57 \mathrm{wt}$. \% in $\mathrm{ChCl}$ and imidazole by adding $5 \mathrm{wt}$. \% PEG [118].

The use of ultrasound irradiation has also been revealed to be efficient by Malaeke et al. [119]. They tested a series of DESs, such as $\mathrm{ChCl} / \mathrm{phenol}, \mathrm{ChCl} / \mathrm{a}$-naphthol, $\mathrm{ChCl} / \mathrm{resorcinol}$ and $\mathrm{ChCl} / \mathrm{maleic}$ acid, and found them to be able to dissolve cellulose. The maximum cellulose solubility (6.10 wt. \%) was found in $\mathrm{ChCl}$ and resorcinol.

Ren et al. also described a system, namely Triethyl-allyl ammonia chloride/oxalic acid, in which, thanks to the presence of the allyl-functionalized choline, the highest cellulose 
solubility among the listed DESs was achieved (6.48 wt. \%). The delocalization of charge obtained by the introduction of the allyl group led to the decrease of the viscosity of the solvent medium, allowing higher accessibility to the substrate, which is then dissolved through the formation of H-bonds [118].

Chlotaray et al. used a hybrid ionic fluid composed of both ILs and DESs in equal molar ratios having a common cation or anion. Glyn-EmimCl was prepared by combining a glyceline (glycerol/ChCl, Glyn) DES with 1-ethyl-3-methylimidazolium chloride (EmimCl). Although the starting material showed moderate (EmimCl) and no (Glyn) dissolution capability, the resultant complex mixture led to a complete dissolution under heating $\left(100^{\circ} \mathrm{C}\right)$ after $3 \mathrm{~h}$. The improved dissolution capability of Glyn-EmimCl was attributed to the synergistic effect of acidic hydrogen present in the imidazolium ring, the hydrogen bonding network between Glyn and EmimCl and the $\mathrm{OH}$ group of the glycerol. Furthermore, the anion chlorine between the Glyn DES and EmimCl presumably plays a crucial role in binding both the components and eventually leading to effective cellulose dissolution. The solvent performance was even increased by coupling MW techniques that accelerate the dissolution process: the same dissolution was already obtained after $6 \mathrm{~s}$ of treatment [120].

\subsection{Derivatization of Cellulose for the Production of Added Value Polymers}

Nano-sized cellulose fibres derived from lignocellulosic sources have captured increasing scientific and industrial interest in recent years. Nanocellulose has superior properties suitable for the production of novel materials, namely lightweight, flexible green electronics and recyclable solar cells $[124,125]$. The most common methods to produce unmodified nanocellulose are based on mechanical, enzymatic and solvent-based pretreatments. However, the most effective has been revealed to be chemical pretreatments since these led to the formation of nanocellulose with a more homogeneous size distribution. In particular, the use of solvents as derivatizing reagents has kept the attention of numerous researchers since it represents an efficient way to minimize waste formation [126].

Usually, the derivatizing solvents react with hydroxyl groups, replacing the hydrogen bond network with the formation of ether, ester, acetal or other derivatives and achieving the dissolution of cellulose (Figure 10).

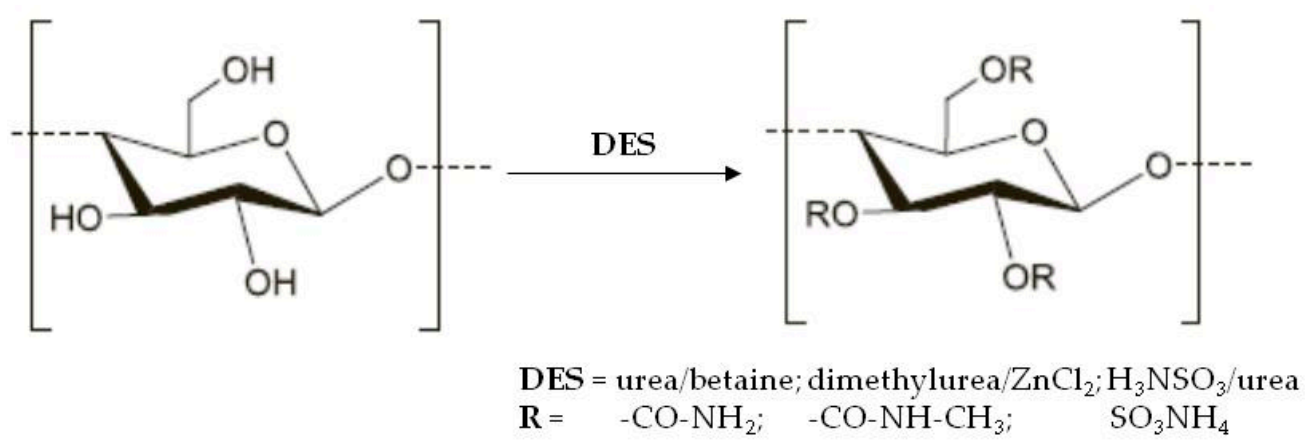

Figure 10. Derivatization of cellulose by using DES.

Traditional derivatizing solvents for cellulose dissolution include trifluoroacetic acid, formic acid, DMF $/ \mathrm{N}_{2} \mathrm{O}_{4}$ and DMSO/paraformaldehyde [111].

At the industrial level, $\mathrm{CS}_{2}$ in $\mathrm{NaOH}$ is used in the viscose process to produce fibres from cellulose. $\mathrm{CS}_{2}$ reacts with hydroxyl groups of cellulose to form soluble cellulose xanthogenate. However, this process is considered unfavourable due to its environmental impacts related to the use of $\mathrm{CS}_{2}$ and the relevant recycling difficulties.

Recently, a large number of studies described the use of DESs as solvents for cellulose derivatization [127-129] and for the production of nanocelluloses [130-133].

The use of DESs in the production of cellulose carbamate (CCA) represents a promising alternative to viscose cellulose for the synthesis of fibre cellulose [134]. CCA is bio-based, 
biodegradable and biocompatible. It is considered an environmentally friendly material and a valid alternative to petroleum-based polymers [135]. CCA also is relatively stable at room temperature, which enables long storage periods [136].

In conventional processes, CCA with a nitrogen content $(\mathrm{N} \%)$ of $1-2.5 \%$ is prepared by using an organic solvent and harsh operative conditions $\left(>135^{\circ} \mathrm{C}\right)$. DESs, thanks to their low price, nontoxicity, biodegradability and biocompatibility, are promising solvents for CCA production. For instance, Keyriläinen et al. [132] reported a case of three urea-based DESs, namely urea: $\mathrm{ChCl}$, urea:betaine $\mathrm{HCl}$ and urea:betaine, for the synthesis of CCA [132]. Among these, the third showed better performances. The correlation between the nitrogen percentage in the fine compound with temperature (ranged between $95^{\circ} \mathrm{C}$ and $120{ }^{\circ} \mathrm{C}$ ), molar ratio of DES/Urea (ranged between 2:1 and 4:1) and cellulose consistency $(5,10,20 \%)$ was studied: the highest N\% content (7.4\%) was achieved using urea:betaine DES 4:1 at $120{ }^{\circ} \mathrm{C}$ and $20 \%$ of cellulose consistency. The main advantage of the use of DESs is that the carbamation process occurs at a lower reaction temperature, and thus, the decomposition of cellulose is minimized.

Another example was reported by Sirviö [137] for the synthesis of cellulose methyl carbamate $(\mathrm{CMeC})$ by allowing cellulose to react with an excess of DESs at an elevated temperature $\left(150{ }^{\circ} \mathrm{C}\right)$. A DES composed of dimethylurea and $\mathrm{ZnCl}_{2}$ was used. $\mathrm{CMeC}$ functional groups were efficiently introduced to cellulose, and the maximum nitrogen content was $1.37 \%$, achieved after a $3 \mathrm{~h}$ reaction time. The degree of polymerization of the original cellulose pulp decreased from 1820 to 686-1200 during the reactions, and no zinc derived from DES during the cellulose carbamation remained in the fibre. The chemical modification of cellulose was assumed to proceed first through the degradation of dimethylurea into methylamine and methylisocyanate, which reacts with the hydroxyl groups of cellulose. The advantage of such a process is that toxic isocyanates are generated in situ from much less harmful dimethylurea.

Sirviö et al. [138] also reported the use of reactive DESs based on sulfamic acid and urea for the synthesis of sulphated cellulose. Cellulose fibres containing a high sulphate group content ( $\mathrm{S} \%$ up to 9.6 ) were obtained in $30 \mathrm{~min}$ at $150{ }^{\circ} \mathrm{C}$ using a modest excess of sulphating chemical compared with cellulose (10:1 molar ratio). Sulphated cellulose could easily be disintegrated into sulphated cellulose nanofibers using mild mechanical disintegration.

\subsection{Direct and Indirect Conversion of Cellulose into Platform Molecules}

In this section, the discussion focuses on the use of DESs for valorising biomassderived substances such as cellulose or simple sugars towards value-added chemicals. Once the lignocellulosic biomass is pretreated, cellulose can be reacted to produce glucose/fructose, as conceptually shown in Figure 7. DESs offer a valid alternative to complete the valorisation of biomasses since they can dissolve a wide range of reactants and consequently change a heterogeneous catalytic mechanism into a homogeneous one. Many examples in the literature report the catalytic conversion in DES of different feedstocks, namely cellulose, fructose or glucose, into a large number of valuable products (Figure 11).

The catalytic performance of DESs is strongly related to the component they are made of: chlorides of transition metals such as $\mathrm{Zn}$ and $\mathrm{Cr}$, mainly combined with $\mathrm{ChCl}$ in different molar ratios, give rise to catalysts with Lewis acid properties [139].

On the other hand, Brønsted acid-type DESs, mainly containing $\mathrm{ChCl}$ combined with organic acids, such as oxalic acid, citric acid, malonic acid and p-toluene sulfonic acid (p-TSA), or alcohols or amides, such as urea, could be prepared [139-141]. Both Lewis and Brønsted acidic DESs have been used in the biomass upgradation to platform compounds such as HMF, furfural, 5-(Chloromethyl)furfural (CMF) and other value-added chemicals. HMF (or its ethyl derivative) is commonly obtained in an aqueous (alcoholic) medium by catalytic dehydration of carbohydrates such as xylose, fructose and glucose using different acid catalytic systems (mineral, solid or metallic acids) [142,143]. The common drawback of these systems is the requirement for relatively high reaction temperatures, which lead to low HMF yields because of the rehydration of the final product. Moreover, the inevitable 
condensation reaction and humin formation under acidic conditions make the separation and purification of HMF considerably challenging.

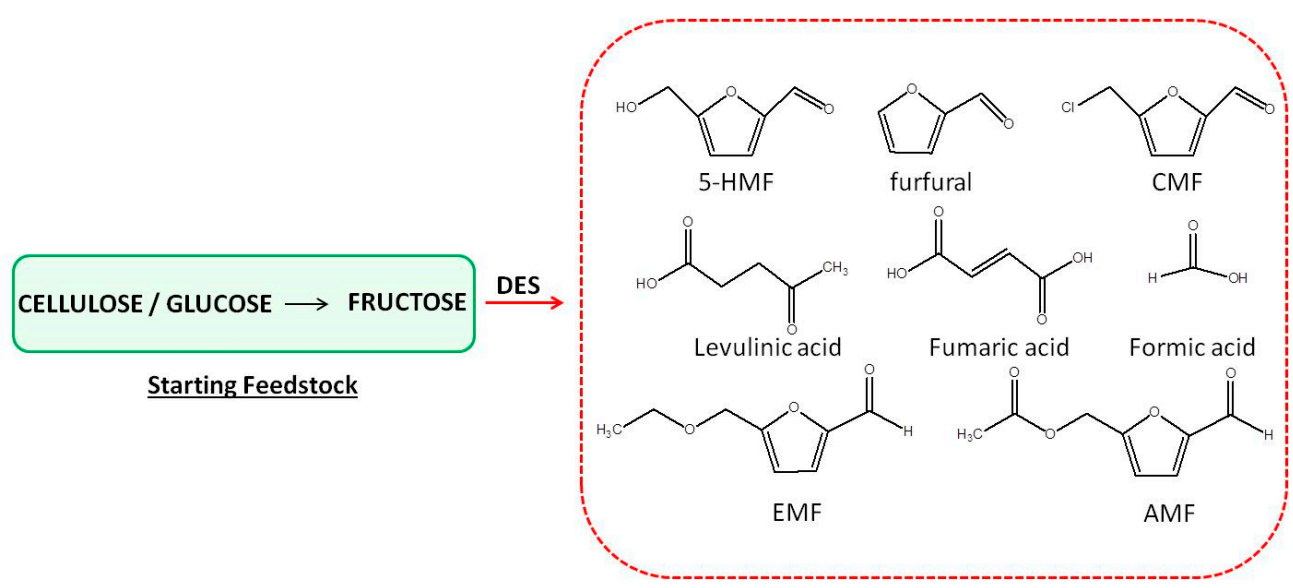

Figure 11. Direct and indirect catalytic conversion of cellulose into platform molecules by using DES.

Table 4 collects a list of DES applications as catalysts to synthesise several valuable compounds starting from fructose or directly from glucose or cellulose. The last two are more desirable as a starting material since fructose is not abundant in nature. Its production cost is very high, limiting its application on a large scale and sustainable production of target compounds. The main product on which the literature is focused is HMF.

Table 4. DESs as catalyst/solvent for the synthesis of platform molecule: glucose and fructose were also included since they can be potentially obtained from biomasses.

\begin{tabular}{|c|c|c|c|c|}
\hline Feedstock & DES & Operative Conditions & Results & Ref. \\
\hline \multirow{5}{*}{ Cellulose } & 3DEACl 3:2oxalic acid & at $170{ }^{\circ} \mathrm{C}$ in $5 \mathrm{~min}, \mathrm{MW}$ reactor & $\begin{array}{l}\text { 38.4\% total conversion (levulinic } \\
\text { acid, HMF, furfural and } \\
\text { formic acid) }\end{array}$ & [144] \\
\hline & $\mathrm{ChCl} / \mathrm{pTSA}$ & $80^{\circ} \mathrm{C}, 30 \mathrm{~min}$ & $93 \%$ yield in $\mathrm{HMF}$ & [145] \\
\hline & Oxalic acid $/ \mathrm{SnCl}_{4}$ & $160^{\circ} \mathrm{C}, 90 \mathrm{~min}$ & $\begin{array}{l}11 \% \text { HMF } \\
227 \% \text { olucese }\end{array}$ & [145] \\
\hline & $\mathrm{ChCl} /$ oxalic acid $+\mathrm{SnCl}_{4}$ & $140^{\circ} \mathrm{C}, 2 \mathrm{~h}$ & 23.5\% HMF yield & [146] \\
\hline & $\mathrm{ChCl} /$ oxalic acid & $180^{\circ} \mathrm{C}, 1 \mathrm{~min}, \mathrm{MW}$ reactor & $\begin{array}{c}76.2 \% \text { of levulinic acid, } 4.07 \% \text { of } \\
\text { HMF, } 5.57 \% \text { of furfural }\end{array}$ & [147] \\
\hline \multirow{4}{*}{ Glucose } & $\mathrm{ChCl}, \mathrm{AlCl}_{3} \cdot 6 \mathrm{H}_{2} \mathrm{O}$, oxalic acid & at $120^{\circ} \mathrm{C}$ within $30 \mathrm{~min}$ & CMF yield of $30 \%$ & [148] \\
\hline & $\mathrm{ChCl}$ /ethylene glycol $+\mathrm{CrCl}_{3}$ & $\mathrm{t} 150^{\circ} \mathrm{C}, 3.64 \mathrm{~min}$ & $42 \%$ yield of $\mathrm{HMF}$ & [149] \\
\hline & $\mathrm{ChCl}, \mathrm{AlCl}_{3} \cdot 6 \mathrm{H}_{2} \mathrm{O}$, oxalic acid & $120^{\circ} \mathrm{C}, 30 \mathrm{~min}$ & CMF yield of $70 \%$ & [148] \\
\hline & $\mathrm{ChCl} / \mathrm{AlCl}_{3}$ & $\begin{array}{c}120^{\circ} \mathrm{C} \text { for } \\
2 \mathrm{~h} \text { and } 14 \mathrm{~h} \\
\text { cosolvent }=\text { EtAc }\end{array}$ & $\begin{array}{l}73.2 \% \text { furan products, including } \\
52.9 \% \text { of } \mathrm{HMF} \text { and } 17.5 \% \text { of AMF }\end{array}$ & [150] \\
\hline \multirow{5}{*}{ Fructose } & $\mathrm{Im} / 1.5 \mathrm{BSA}$ & $100{ }^{\circ} \mathrm{C}, 3 \mathrm{~min}$ & $90.1 \% \mathrm{HMF}$ & [151] \\
\hline & $\mathrm{Ch} / \mathrm{pTSA}$ & $80^{\circ} \mathrm{C}, 1 \mathrm{~h}$ & $90.7 \% \mathrm{HMF}$ & [140] \\
\hline & [Emim] $\mathrm{Cl}$ /isopropanol & $25^{\circ} \mathrm{C}, 3 \mathrm{~h}$ Cat $=[\mathrm{HNMP}] \mathrm{Cl}$ & $89 \% \mathrm{HMF}$ & [141] \\
\hline & $\mathrm{ChCl} / \mathrm{AlCl}_{3} \cdot 6 \mathrm{H}_{2} \mathrm{O}$ & $120^{\circ} \mathrm{C}, 5 \mathrm{~h}$ & $50.3 \%$ of CMF $8.1 \%$ of $\mathrm{HMF}$ & [152] \\
\hline & $\begin{array}{c}\text { DES/acetonitrile }(\mathrm{MeCN}) \\
\text { biphasic reaction }\end{array}$ & $100^{\circ} \mathrm{C}, 4 \mathrm{~h}$ & $90.3 \% \mathrm{HMF}$ & [153] \\
\hline
\end{tabular}

The dehydration of fructose into HMF using DESs as media has been reported by numerous researchers. The results showed that the Brønsted acidic DESs, particularly $\mathrm{ChCl} /$ malonic acid, $\mathrm{ChCl}$ /oxalic acid $2 \mathrm{H}_{2} \mathrm{O}$ and $2 \mathrm{ChCl}$ / citric acid $\mathrm{H}_{2} \mathrm{O}$, were adequate to convert fructose to HMF (91-100\%). Conversely, the Lewis acidic DESs, $\mathrm{ChCl}: 2 \mathrm{ZnCl}_{2}$ and $\mathrm{ChCl}: 2 \mathrm{CrCl}_{3} 6 \mathrm{H}_{2} \mathrm{O}$, were inefficient in producing $\mathrm{HMF}$ [139]. The catalytic mechanism 
consistently reports the formation of a hydrogen bond between organic acid or alcohol and fructose, thus promoting its transformation rates.

Assanosi et al. [140] used an acidic DES, ChCl:p-TSA, to dehydrate fructose to the final HMF. The highest HMF yield, $90.7 \%$, was obtained at $80^{\circ} \mathrm{C}$ in $1 \mathrm{~h}$ with a feed ratio of $2.5 \%$. The example reported by Zhang et al. [141] is also impressive, in which a DES composed of equal moles of [Emim] $\mathrm{Cl}$ (Emim = 1-ethyl-3-methylimidazolium chloride) and isopropanol catalysed by [HNMP]Cl (N-methyl-2-pyrrolidonium chloride) could convert fructose into HMF at room temperature thanks to hydrogen bonds formed between the alcohol (isopropanol) and the intermediates/ILs ([Emim]Cl and [HNMP]Cl) that strongly affect the rates of the process.

Ruan et al. [151] used a bifunctional DES composed of imidazole (Im) and benzene sulfonic acid (BSA) in 1:1.5 molar ratio to perform as both catalyst and solvent in the dehydration reaction. With a $10 \%$ DES and after a short reaction time of $3 \mathrm{~min}$ at $100{ }^{\circ} \mathrm{C}$, the HMF yield reached $90.1 \%$. They found that the solvent effect of the DES was due to the formation of H-bonds between $\mathrm{Im}^{+}$and/or BSA components and fructose.

Synthesis of HMF starting from glucose and catalysed by DESs has also been recently reported in the literature [144,148-150].

Zhang et al. [149] used different inorganic salts added to several DESs to convert glucose to HMF in microreactors. At $150{ }^{\circ} \mathrm{C}$ and in less than $4 \mathrm{~min}$, the HMF yield reached $42 \%$. Studies on the catalytic mechanism revealed a synergistic effect between $\mathrm{CrCl}_{3}$ and $\mathrm{ChCl}$ of the DES (ChCl:2ethylene glycol) to achieve better yields. Upon conversion of glucose to fructose, the dehydration of fructose to HMF was obtained under the influence of the $[\mathrm{ChCl}]^{+}\left[\mathrm{CrCl}_{4}\right]^{-}$complex. The reusability of the $(\mathrm{ChCl}$ :2ethylene glycol $)+\mathrm{CrCl}_{3}$ was also investigated and found to be satisfactory after three runs with a $38 \%$ yield of HMF.

Chen et al. reported the successful conversion of glucose into CMF. CMF is a platform molecule that has attracted much attention for the preparation of monomers, biofuels and versatile chemicals, including 2,5-furandicarboxylate, alkoxymethylfurfurals, $\delta$-aminolevulinic acid and gasoline-like C8-C10 hydrocarbons. Compared with HMF, CMF is more stable and has excellent hydrophobicity, which markedly facilitates the isolation and purification processes. The major drawbacks in CMF production are concentrated acids and harsh conditions that require expensive methodologies to avoid corrosion of plants and safety measures. The use of DESs is then proposed as a novel method to eliminate the dependence on concentrated $\mathrm{HCl}$. The DES-based synthesis of CMF with a three-constituent DES including $\mathrm{ChCl}, \mathrm{AlCl}_{3} 6 \mathrm{H}_{2} \mathrm{O}$ and oxalic acid (OA) results in a $\mathrm{CMF}$ yield up to $70 \%$ from glucose at $120^{\circ} \mathrm{C}$ within $30 \mathrm{~min}$.

Finally, cellulose could be used as a biomass to obtain added-value chemicals. Generally, the mechanism consists of the hydrolysis of cellulose into glucose, dehydration of glucose to HMF and eventually conversion of HMF into other compounds, such as levulinic acid or formic acid. It is not easy to obtain a good yield and selectivity in the direct conversion of cellulose because of the insoluble nature of cellulose, as already explained previously. Therefore, in this case, the use of DESs acquires importance both for the solubilization issue and the catalytic aspect. A list of DESs that resulted in being efficient in the conversion of cellulose is reported in Table 4 [146,147,154].

Arslanoğlu used sunflower stalk as biomass with high cellulose content to obtain several products of interest $[144,155]$. The process involved employs a catalytic DES composed of DEACl (N,N-di-ethyl ethanol ammonium chloride) and oxalic acid in a 3:2 molar ratio in an MW reactor to convert the cellulosic biomass. The conversion yield of the cellulose was examined at different temperatures and reaction times. At the optimum conditions, i.e., $170{ }^{\circ} \mathrm{C}$ within $5 \mathrm{~min}$, the maximum carbon conversion was $38.4 \%$, with the highest yield relating to levulinic acid followed by formic acid, furfural and HMF.

Lang et al. [146] reported a two-phase system formed by DES ( $\mathrm{ChCl} /$ oxalic acid) and chosen solvents in order to overcome problems of the separation of products. Metal chloride $\left(\mathrm{SnCl}_{4}\right)$ was used as a catalyst to study the degradation of cellulose to produce HMF and glucose. Among all the tested solvents, ethyl n-butyrate has the best extraction 
effect on HMF. The use of a biphasic system also has a positive impact on the final yield of HMF and glucose: at a temperature of $140{ }^{\circ} \mathrm{C}$ and a reaction time of $120 \mathrm{~min}$, the yields of glucose and HMF reached the maximum, which were $23.5 \%$ and $29.8 \%$, respectively. However, DES was not reusable as the yield of glucose and HMF significantly decreased.

\section{Conclusions: Perspectives and Criticisms on the Use of DES}

As reported in Table 2, DESs offer valid alternative reaction media to carry out the chemical valorisation of biomasses. With a polarity comparable to that of ILs, DESs produce fewer impacts than ILs, as they are composed of natural biodegradable components. The intrinsic nature of establishing the H-bond also confers unique properties that apply to the electro-polishing of metals, metal electrodeposition and metal extraction [29]. DESs should be extended to several new biomasses to implement the biorefinery scenario with new solutions and unexplored options for achieving new base chemicals [156].

The application of DESs in lignocellulosic biomass pretreatment needs to consider several aspects for reaching sustainability. The tolerance of Cellulases to the presence of traces of DESs on the pretreated biomasses and the stability, recoverability and reuse of DESs play a crucial role from an economic point of view $[93,157]$. For example, lactic acid could dimerize to produce lactide by changing the nature of the possibly recovered DES [157]. At the same time, acids may directly bind to the biomass's hydroxyl group, resulting in a final loss.

The initial content of biomass with respect to the DES also represents another key point for financial sustainability. Table 3 reported that the usual range of lignocellulosic biomass is a $5-10 \%$ concentration. Recently, a twin-screw extruder was employed for the continuous pretreatment of sorghum bagasse, mediated by a neutral $\mathrm{pH}$ DES ChCl:glycerol. The extrusion process showed a high pretreatment performance at a biomass loading as high as $50 \%$, with both glucose and xylose yields reaching up to $85 \%$. These sugar yields were much higher than those achieved from batch-type pretreatment in high-pressure glass reactors at a biomass loading of $10 \%$. The DES-mediated extrusion effectively pulverized and fibrillated the biomass and decreased the crystallinity. Additionally, the characterization of lignin streams demonstrated that lignin maintained the structural characteristics during the extrusion. The results show that the DES-mediated extrusion process is a promising technology that enables the continuous pretreatment of lignocellulosic biomass at a high solid loading [158].

In the future, possible developments are remarkably demanded to introduce more complex integrated systems which allow for maximizing proficiency and affectability [41,58]. Although a considerable number (over 200 examples) of DESs have already been studied and investigated, research should continue to develop new solutions having tailored properties to specific applications [159]. Moreover, investigation into the mechanism and the determination of correlations between structures of DESs and the relevant appropriateness of applications needs to be continuously implemented [160]. In such a context, the study of DESs in the field of the lignocellulosic biomass valorisation could be considered to be at its native state, and further deep investigation should be essential. In particular, the dissolution of cellulose, as a sort of emulation of some ILs, could help in developing new routes of valorisation. The intensification of processes may represent a new frontier for this kind of process: if the pretreatment step is combined with the conversion of polymeric subunits into the different target molecules in a single step, a greener valorisation process could eventually be achieved.

Author Contributions: Conceptualization, C.P. and A.A.; methodology, C.P.; software, E.S.; data curation, writing — original draft preparation, visualization, C.P., A.A. and E.S.; supervision, C.P.; project administration, C.P.; funding acquisition, C.P. All authors have read and agreed to the published version of the manuscript.

Funding: This research received no external funding.

Institutional Review Board Statement: Not applicable. 
Informed Consent Statement: Not applicable.

Data Availability Statement: The data presented in this study are available on request from the corresponding author.

Conflicts of Interest: The authors declare no conflict of interest.

\section{References}

1. Nagarajan, D.; Chang, J.S.; Lee, D.J. Pretreatment of microalgal biomass for efficient biohydrogen production-Recent insights and future perspectives. Bioresour. Technol. 2020, 302, 122871. [CrossRef]

2. Kumar, B.; Bhardwaj, N.; Agrawal, K.; Chaturvedi, V.; Verma, P. Current perspective on pretreatment technologies using lignocellulosic biomass: An emerging biorefinery concept. Fuel Process. Technol. 2020, 199, 106244. [CrossRef]

3. Haldar, D.; Purkait, M.K. Lignocellulosic conversion into value-added products: A review. Process Biochem. 2020, 89, 110-133. [CrossRef]

4. Roy, R.; Rahman, M.S.; Raynie, D.E. Recent advances of greener pretreatment technologies of lignocellulose. Curr. Res. Green Sustain. Chem. 2020, 3, 100035. [CrossRef]

5. Liu, X.; Bouxin, F.P.; Fan, J.; Budarin, V.L.; Hu, C.; Clark, J.H. Recent Advances in the Catalytic Depolymerization of Lignin towards Phenolic Chemicals: A Review. ChemSusChem 2020, 13, 4296-4317. [CrossRef]

6. Zhuang, X.; Wang, W.; Yu, Q.; Qi, W.; Wang, Q.; Tan, X.; Zhou, G.; Yuan, Z. Liquid hot water pretreatment of lignocellulosic biomass for bioethanol production accompanying with high valuable products. Bioresour. Technol. 2016, 199, 68-75. [CrossRef]

7. Ciesielski, P.N.; Pecha, M.B.; Lattanzi, A.M.; Bharadwaj, V.S.; Crowley, M.F.M.F.; Bu, L.; Vermaas, J.V.; Steirer, K.X.; Crowley, M.F.M.F. Advances in Multiscale Modeling of Lignocellulosic Biomass. ACS Sustain. Chem. Eng. 2020, 8, 3512-3531. [CrossRef]

8. Guerriero, G.; Hausman, J.-F.; Strauss, J.; Ertan, H.; Siddiqui, K.S. Lignocellulosic biomass: Biosynthesis, degradation, and industrial utilization. Eng. Life Sci. 2016, 16, 1-16. [CrossRef]

9. Nishimura, H.; Kamiya, A.; Nagata, T.; Katahira, M.; Watanabe, T. Direct evidence for $\alpha$ ether linkage between lignin and carbohydrates in wood cell walls. Sci. Rep. 2018, 8, 1-11. [CrossRef]

10. Haldar, D.; Purkait, M.K. A review on the environment-friendly emerging techniques for pretreatment of lignocellulosic biomass: Mechanistic insight and advancements. Chemosphere 2021, 264, 128523. [CrossRef]

11. Fearon, O.; Kuitunen, S.; Ruuttunen, K.; Alopaeus, V.; Vuorinen, T. Detailed Modeling of Kraft Pulping Chemistry. Delignification. Ind. Eng. Chem. Res. 2020, 59, 12977-12985. [CrossRef]

12. Mohammad, J.T.; Keikhosro, K. Pretreatment of Lignocellulosic Wastes to Improve Ethanol and Biogas Production: A Review. Int. J. Mol. Sci. 2008, 9, 1621-1651.

13. Brodeur, G.; Yau, E.; Badal, K.; Collier, J.; Ramachandran, K.B.; Ramakrishnan, S. Chemical and Physicochemical Pretreatment of Lignocellulosic Biomass: A Review. Res. Enzym. Res. 2011, 2011, 17.

14. Sihvonen, M.; Järvenpää, E.; Hietaniemi, V.; Huopalahti, R. Advances in supercritical carbon dioxide technologies. Trends Food Sci. Technol. 1999. [CrossRef]

15. Stolarski, M.J.; Warmiński, K.; Krzyżaniak, M.; Tyśkiewicz, K.; Olba-Zięty, E.; Graban, Ł.; Lajszner, W.; Załuski, D.; Wiejak, R.; Kamiński, P.; et al. How does extraction of biologically active substances with supercritical carbon dioxide affect lignocellulosic biomass properties? Wood Sci. Technol. 2020. [CrossRef]

16. Yoo, C.G.; Pu, Y.; Ragauskas, A.J. Ionic liquids: Promising green solvents for lignocellulosic biomass utilization. Curr. Opin. Green Sustain. Chem. 2017, 5, 5-11. [CrossRef]

17. Xia, Z.; Li, J.; Zhang, J.; Zhang, X.; Zheng, X.; Zhang, J. Processing and valorization of cellulose, lignin and lignocellulose using ionic liquids. J. Bioresour. Bioprod. 2020, 5, 79-95. [CrossRef]

18. Zhu, Z.; Liu, Y.; Yang, X.; McQueen-Mason, S.J.; Gomez, L.D.; Macquarrie, D.J. Comparative evaluation of microwave-assisted acid, alkaline, and inorganic salt pretreatments of sugarcane bagasse for sugar recovery. Biomass Convers. Biorefin. 2020. [CrossRef]

19. Mikulski, D.; Kłosowski, G. Microwave-assisted dilute acid pretreatment in bioethanol production from wheat and rye stillages. Biomass Bioenergy 2020, 136, 105528. [CrossRef]

20. Zhang, W.; Liu, J.; Wang, Y.; Sun, J.; Huang, P.; Chang, K. Effect of ultrasound on ionic liquid-hydrochloric acid pretreatment with rice straw. Biomass Convers. Biorefin. 2020. [CrossRef]

21. Qing, Q.; Hu, R.; He, Y.; Zhang, Y.; Wang, L. Investigation of a novel acid-catalyzed ionic liquid pretreatment method to improve biomass enzymatic hydrolysis conversion. Appl. Microbiol. Biotechnol. 2014, 98, 5275-5286. [CrossRef]

22. Mora-Pale, M.; Meli, L.; Doherty, T.V.; Linhardt, R.J.; Dordick, J.S. Room temperature ionic liquids as emerging solvents for the pretreatment of lignocellulosic biomass. Biotechnol. Bioeng. 2011, 108, 1229-1245. [CrossRef]

23. Morais, E.S.; Lopes, A.M.d.C.; Freire, M.G.; Freire, C.S.R.; Coutinho, J.A.P.; Silvestre, A.J.D. Use of Ionic Liquids and Deep Eutectic Solvents in Polysaccharides Dissolution and Extraction Processes towards Sustainable Biomass Valorization. Molecules 2020, 25, 3652. [CrossRef]

24. Wahlström, R.; Hiltunen, J.; Pitaluga De Souza Nascente Sirkka, M.; Vuoti, S.; Kruus, K. Comparison of three deep eutectic solvents and 1-ethyl-3-methylimidazolium acetate in the pretreatment of lignocellulose: Effect on enzyme stability, lignocellulose digestibility and one-pot hydrolysis. RSC Adv. 2016, 6, 68100-68110. [CrossRef] 
25. Wahlström, R.; Hiltunen, J.; de Souza Nascente Sirkka, P.M.; Kruus, K.; Vuoti, S. Deep eutectic solvents and ionic liquids in enzymatic lignocellulose hydrolysis. In Proceedings of the NWBC 2015-6th Nordic Wood Biorefinery Conference, Helsinki, Finland, 20-22 October 2015; pp. 326-331.

26. Xia, S.; Baker, G.A.; Li, H.; Ravula, S.; Zhao, H. Aqueous ionic liquids and deep eutectic solvents for cellulosic biomass pretreatment and saccharification. RSC Adv. 2014, 4, 10586-10596. [CrossRef]

27. Abbott, A.P.; Capper, G.; Davies, D.L.; Rasheed, R.K.; Tambyrajah, V. Novel solvent properties of choline chloride/urea mixtures. Chem. Commun. 2003, 70-71. [CrossRef] [PubMed]

28. Zhao, H.; Baker, G.A. Ionic liquids and deep eutectic solvents for biodiesel synthesis: A review. J. Chem. Technol. Biotechnol. 2013, 88, 3-12. [CrossRef]

29. Smith, E.L.; Abbott, A.P.; Ryder, K.S. Deep Eutectic Solvents (DESs) and Their Applications. Chem. Rev. 2014, 114, 11060-11082. [CrossRef] [PubMed]

30. Hossain, M.A.; Rahaman, M.S.; Yelle, D.; Shang, H.; Sun, Z.; Renneckar, S.; Dong, J.; Tulaphol, S.; Sathitsuksanoh, N. Effects of polyol-based deep eutectic solvents on the efficiency of rice straw enzymatic hydrolysis. Ind. Crops Prod. 2021, 167, 113480. [CrossRef]

31. Wang, R.; Wang, K.; Zhou, M.; Xu, J.; Jiang, J. Efficient fractionation of moso bamboo by synergistic hydrothermal-deep eutectic solvents pretreatment. Bioresour. Technol. 2021, 328, 124873. [CrossRef]

32. Li, C.; Huang, C.; Zhao, Y.; Zheng, C.; Su, H.; Zhang, L.; Luo, W.; Zhao, H.; Wang, S.; Huang, L.J. Effect of choline-based deep eutectic solvent pretreatment on the structure of cellulose and lignin in Bagasse. Processes 2021, 9, 384. [CrossRef]

33. Li, G.; Jiang, Y.; Liu, X.; Deng, D. New levulinic acid-based deep eutectic solvents: Synthesis and physicochemical property determination. J. Mol. Liq. 2016, 222, 201-207. [CrossRef]

34. De, D.; Naga Sai, M.S.; Aniya, V.; Satyavathi, B. Strategic biorefinery platform for green valorization of agro-industrial residues: A sustainable approach towards biodegradable plastics. J. Clean. Prod. 2021, 290, 125184. [CrossRef]

35. Ji, Q.; Yu, X.; Yagoub, A.E.G.A.; Chen, L.; Zhou, C. Efficient removal of lignin from vegetable wastes by ultrasonic and microwaveassisted treatment with ternary deep eutectic solvent. Ind. Crops Prod. 2020, 149. [CrossRef]

36. Bahadori, L.; Chakrabarti, M.H.; Mjalli, F.S.; Alnashef, I.M.; Manan, N.S.A.; Hashim, M.A. Physicochemical properties of ammonium-based deep eutectic solvents and their electrochemical evaluation using organometallic reference redox systems. Electrochim. Acta 2013, 113, 205-211. [CrossRef]

37. Hayyan, A.; Mjalli, F.S.; Alnashef, I.M.; Al-Wahaibi, Y.M.; Al-Wahaibi, T.; Hashim, M.A.; Hashim, A. Glucose-based deep eutectic solvents: Physical properties. J. Mol. Liq. 2013. [CrossRef]

38. Craveiro, R.; Aroso, I.; Flammia, V.; Carvalho, T.; Viciosa, M.T.; Dionísio, M.; Barreiros, S.; Reis, R.L.; Duarte, A.R.C.; Paiva, A. Properties and thermal behavior of natural deep eutectic solvents. J. Mol. Liq. 2016, 215, 534-540. [CrossRef]

39. Gautam, R.; Kumar, N.; Lynam, J.G. Theoretical and experimental study of choline chloride-carboxylic acid deep eutectic solvents and their hydrogen bonds. J. Mol. Struct. 2020, 1222. [CrossRef]

40. Cui, Y.; Li, C.; Yin, J.; Li, S.; Jia, Y.; Bao, M. Design, synthesis and properties of acidic deep eutectic solvents based on choline chloride. J. Mol. Liq. 2017, 236, 338-343. [CrossRef]

41. Wang, Y.; Meng, X.; Jeong, K.; Li, S.; Leem, G.; Kim, K.H.; Pu, Y.; Ragauskas, A.J.; Yoo, C.G. Investigation of a lignin-based deep eutectic solvent using p-hydroxybenzoic acid for efficient woody biomass conversion. ACS Sustain. Chem. Eng. 2020, 8 , 12542-12553. [CrossRef]

42. García, G.; Aparicio, S.; Ullah, R.; Atilhan, M. Deep eutectic solvents: Physicochemical properties and gas separation applications. Energy Fuels 2015. [CrossRef]

43. Zhang, Q.; De Oliveira Vigier, K.; Royer, S.; Jérôme, F. Deep eutectic solvents: Syntheses, properties and applications. Chem. Soc. Rev. 2012. [CrossRef] [PubMed]

44. Chen, W.; Bai, X.; Xue, Z.; Mou, H.; Chen, J.; Liu, Z.; Mu, T. The formation and physicochemical properties of PEGylated deep eutectic solvents. New J. Chem. 2019, 43, 8804-8810. [CrossRef]

45. Naser, J.; Mjalli, F.; Jibril, B.; Al-Hatmi, S.; Gano, Z. Potassium Carbonate as a Salt for Deep Eutectic Solvents. Int. J. Chem. Eng. Appl. 2013, 114-118. [CrossRef]

46. Tan, Y.T.; Ngoh, G.C.; Chua, A.S.M. Evaluation of fractionation and delignification efficiencies of deep eutectic solvents on oil palm empty fruit bunch. Ind. Crops Prod. 2018, 123, 271-277. [CrossRef]

47. Adeyemi, I.; Abu-Zahra, M.R.M.; AlNashef, I.M. Physicochemical properties of alkanolamine-choline chloride deep eutectic solvents: Measurements, group contribution and artificial intelligence prediction techniques. J. Mol. Liq. 2018, 256, 581-590. [CrossRef]

48. Zhao, Z.; Chen, X.; Ali, M.F.; Abdeltawab, A.A.; Yakout, S.M.; Yu, G. Pretreatment of wheat straw using basic ethanolamine-based deep eutectic solvents for improving enzymatic hydrolysis. Bioresour. Technol. 2018, 263, 325-333. [CrossRef]

49. Satlewal, A.; Agrawal, R.; Bhagia, S.; Sangoro, J.; Ragauskas, A.J. Natural deep eutectic solvents for lignocellulosic biomass pretreatment: Recent developments, challenges and novel opportunities. Biotechnol. Adv. 2018, 36, 2032-2050. [CrossRef] [PubMed]

50. Kalhor, P.; Ghandi, K. Deep eutectic solvents for pretreatment, extraction, and catalysis of biomass and food waste. Molecules 2019, 24, 4012. [CrossRef] 
51. Sosa, F.H.B.; Abranches, D.O.; Da Costa Lopes, A.M.; Coutinho, J.A.P.; Da Costa, M.C. Kraft Lignin Solubility and Its Chemical Modification in Deep Eutectic Solvents. ACS Sustain. Chem. Eng. 2020, 8, 18577-18589. [CrossRef]

52. Hayyan, M.; Hashim, M.A.; Hayyan, A.; Al-Saadi, M.A.; AlNashef, I.M.; Mirghani, M.E.S.; Saheed, O.K. Are deep eutectic solvents benign or toxic? Chemosphere 2013. [CrossRef]

53. Choi, Y.H.; van Spronsen, J.; Dai, Y.; Verberne, M.; Hollmann, F.; Arends, I.W.C.E.; Witkamp, G.J.; Verpoorte, R. Are natural deep eutectic solvents the missing link in understanding cellular metabolism and physiology? Plant. Physiol. 2011. [CrossRef] [PubMed]

54. Zulkefli, S.; Abdulmalek, E.; Abdul Rahman, M.B. Pretreatment of oil palm trunk in deep eutectic solvent and optimization of enzymatic hydrolysis of pretreated oil palm trunk. Renew. Energy 2017. [CrossRef]

55. Francisco, M.; Van Den Bruinhorst, A.; Kroon, M.C. Low-transition-temperature mixtures (LTTMs): A new generation of designer solvents. Angew. Chem. Int. Ed. 2013, 52, 3074-3085. [CrossRef]

56. Liu, Y.Y.; Chen, W.; Xia, Q.; Guo, B.; Wang, Q.; Liu, S.; Liu, Y.Y.; Li, J.; Yu, H. Efficient Cleavage of Lignin-Carbohydrate Complexes and Ultrafast Extraction of Lignin Oligomers from Wood Biomass by Microwave-Assisted Treatment with Deep Eutectic Solvent ChemSusChem 2017, 10, 1692-1700. [CrossRef] [PubMed]

57. Chen, Y.; Mu, T. Application of deep eutectic solvents in biomass pretreatment and conversion. Green Energy Environ. 2019, 4, 95-115. [CrossRef]

58. Kim, K.H.; Eudes, A.; Jeong, K.; Yoo, C.G.; Kim, C.S.; Ragauskas, A. Integration of renewable deep eutectic solvents with engineered biomass to achieve a closed-loop biorefinery. Proc. Natl. Acad. Sci. USA 2019, 116, 13816-13824. [CrossRef] [PubMed]

59. Yu, Q.; Song, Z.; Zhuang, X.; Liu, L.; Qiu, W.; Shi, J.; Wang, W.; Li, Y.; Wang, Z.; Yuan, Z. Catalytic conversion of herbal residue carbohydrates to furanic derivatives in a deep eutectic solvent accompanied by dissolution and recrystallisation of choline chloride. Cellulose 2019, 26. [CrossRef]

60. Ling, Z.; Tang, W.; Su, Y.; Shao, L.; Wang, P.; Ren, Y.; Huang, C.; Lai, C.; Yong, Q. Promoting enzymatic hydrolysis of aggregated bamboo crystalline cellulose by fast microwave-assisted dicarboxylic acid deep eutectic solvents pretreatments. Bioresour. Technol. 2021, 333, 125122. [CrossRef]

61. Lin, X.; Liu, Y.; Zheng, X.; Qureshi, N. High-efficient cellulosic butanol production from deep eutectic solvent pretreated corn stover without detoxification. Ind. Crops Prod. 2021, 162. [CrossRef]

62. Oh, Y.; Park, S.; Jung, D.; Oh, K.K.; Lee, S.H. Effect of hydrogen bond donor on the choline chloride-based deep eutectic solvent-mediated extraction of lignin from pine wood. Int. J. Biol. Macromol. 2020, 165, 187-197. [CrossRef]

63. Hu, S.; Meng, F.; Huang, D.; Huang, J.; Lou, W. Hydrolysis of corn stover pretreated by DESs with carbon-based solid acid catalyst. SN Appl. Sci. 2020, 2. [CrossRef]

64. Ling, Z.; Guo, Z.; Huang, C.; Yao, L.; Xu, F. Deconstruction of oriented crystalline cellulose by novel levulinic acid based deep eutectic solvents pretreatment for improved enzymatic accessibility. Bioresour. Technol. 2020, 305, 123025. [CrossRef]

65. Shen, X.J.; Wen, J.L.; Mei, Q.Q.; Chen, X.; Sun, D.; Yuan, T.Q.; Sun, R.C. Facile fractionation of lignocelluloses by biomass-derived deep eutectic solvent (DES) pretreatment for cellulose enzymatic hydrolysis and lignin valorization. Green Chem. 2019, 21, 275-283. [CrossRef]

66. Chen, Y.; Zhang, L.; Yu, J.; Lu, Y.; Jiang, B.; Fan, Y.; Wang, Z. High-purity lignin isolated from poplar wood meal through dissolving treatment with deep eutectic solvents. R. Soc. Open Sci. 2019, 6. [CrossRef] [PubMed]

67. Satlewal, A.; Agrawal, R.; Das, P.; Bhagia, S.; Pu, Y.; Puri, S.K.; Ramakumar, S.S.V.; Ragauskas, A.J. Assessing the Facile Pretreatments of Bagasse for Efficient Enzymatic Conversion and Their Impacts on Structural and Chemical Properties. ACS Sustain. Chem. Eng. 2019, 7, 1095-1104. [CrossRef]

68. Wang, Z.-K.; Hong, S.S.; Wen, J.-L.; Ma, C.-Y.; Tang, L.; Jiang, H.; Chen, J.-J.; Li, S.; Shen, X.-J.; Yuan, T.-Q. Lewis Acid-Facilitated Deep Eutectic Solvent (DES) Pretreatment for Producing High-Purity and Antioxidative Lignin. ACS Sustain. Chem. Eng. 2020, 8 , 1050-1057. [CrossRef]

69. Tian, D.; Guo, Y.; Hu, J.; Yang, G.; Zhang, J.; Luo, L.; Xiao, Y.; Deng, S.; Deng, O.; Zhou, W.; et al. Acidic deep eutectic solvents pretreatment for selective lignocellulosic biomass fractionation with enhanced cellulose reactivity. Int. J. Biol. Macromol. 2020, 142, 288-297. [CrossRef]

70. Liang, X.; Fu, Y.; Chang, J. Effective separation, recovery and recycling of deep eutectic solvent after biomass fractionation with membrane-based methodology. Sep. Purif. Technol. 2019, 210, 409-416. [CrossRef]

71. Tan, Y.T.; Ngoh, G.C.; Chua, A.S.M. Effect of functional groups in acid constituent of deep eutectic solvent for extraction of reactive lignin. Bioresour. Technol. 2019, 281, 359-366. [CrossRef] [PubMed]

72. Hou, X.D.; Li, A.L.; Lin, K.P.; Wang, Y.Y.; Kuang, Z.Y.; Cao, S.L. Insight into the structure-function relationships of deep eutectic solvents during rice straw pretreatment. Bioresour. Technol. 2018, 249, 261-267. [CrossRef] [PubMed]

73. Shen, X.J.; Chen, T.; Wang, H.M.; Mei, Q.; Yue, F.; Sun, S.; Wen, J.L.; Yuan, T.Q.; Sun, R.C. Structural and Morphological Transformations of Lignin Macromolecules during Bio-Based Deep Eutectic Solvent (DES) Pretreatment. ACS Sustain. Chem. Eng. 2020, 8, 2130-2137. [CrossRef]

74. Fernandes, C.; Melro, E.; Magalhães, S.; Alves, L.; Craveiro, R.; Filipe, A.; Valente, A.J.M.; Martins, G.; Antunes, F.E.; Romano, A.; et al. New deep eutectic solvent assisted extraction of highly pure lignin from maritime pine sawdust (Pinus pinaster Ait.). Int. J. Biol. Macromol. 2021, 177, 294-305. [CrossRef] [PubMed] 
75. Kandanelli, R.; Thulluri, C.; Mangala, R.; Rao, P.V.C.; Gandham, S.; Velankar, H.R. A novel ternary combination of deep eutectic solvent-alcohol (DES-OL) system for synergistic and efficient delignification of biomass. Bioresour. Technol. 2018, 265, 573-576. [CrossRef]

76. Wang, Z.K.; Shen, X.J.; Chen, J.J.; Jiang, Y.Q.; Hu, Z.Y.; Wang, X.; Liu, L. Lignocellulose fractionation into furfural and glucose by AlCl3-catalyzed DES/MIBK biphasic pretreatment. Int. J. Biol. Macromol. 2018, 117, 721-726. [CrossRef] [PubMed]

77. Li, P.; Zhang, Q.; Zhang, X.X.; Zhang, X.X.; Pan, X.; Xu, F. Subcellular dissolution of xylan and lignin for enhancing enzymatic hydrolysis of microwave assisted deep eutectic solvent pretreated Pinus bungeana Zucc. Bioresour. Technol. 2019, 288. [CrossRef] [PubMed]

78. Ji, Q.; Yu, X.; Yagoub, A.E.G.A.; Chen, L.; Mustapha, A.T.; Zhou, C. Enhancement of lignin removal and enzymolysis of sugarcane bagasse by ultrasound-assisted ethanol synergized deep eutectic solvent pretreatment. Renew. Energy 2021, 172, 304-316. [CrossRef]

79. Alvarez-Vasco, C.; Ma, R.; Quintero, M.; Guo, M.; Geleynse, S.; Ramasamy, K.K.; Wolcott, M.; Zhang, X. Unique low-molecularweight lignin with high purity extracted from wood by deep eutectic solvents (DES): A source of lignin for valorization. Green Chem. 2016, 18, 5133-5141. [CrossRef]

80. Pan, M.; Zhao, G.; Ding, C.; Wu, B.; Lian, Z.; Lian, H. Physicochemical transformation of rice straw after pretreatment with a deep eutectic solvent of choline chloride/urea. Carbohydr. Polym. 2017, 176. [CrossRef]

81. Yu, Q.; Zhang, A.; Wang, W.; Chen, L.; Bai, R.; Zhuang, X.; Wang, Q.; Wang, Z.; Yuan, Z. Deep eutectic solvents from hemicellulosederived acids for the cellulosic ethanol refining of Akebia' herbal residues. Bioresour. Technol. 2018. [CrossRef]

82. Xu, H.; Kong, Y.Y.; Peng, J.; Song, X.; Liu, Y.; Su, Z.; Li, B.; Gao, C.; Tian, W. Comprehensive analysis of important parameters of choline chloride-based deep eutectic solvent pretreatment of lignocellulosic biomass. Bioresour. Technol. 2021, $319,124209$. [CrossRef]

83. Chen, Z.; Bai, X.; Lusi, A.; Zhang, H.; Wan, C. Insights into Structural Changes of Lignin toward Tailored Properties during Deep Eutectic Solvent Pretreatment. ACS Sustain. Chem. Eng. 2020, 8, 9783-9793. [CrossRef]

84. Hong, S.; Shen, X.J.; Pang, B.; Xue, Z.; Cao, X.F.; Wen, J.L.; Sun, Z.H.; Lam, S.S.; Yuan, T.Q.; Sun, R.C. In-depth interpretation of the structural changes of lignin and formation of diketones during acidic deep eutectic solvent pretreatment. Green Chem. 2020, 22, 1851-1858. [CrossRef]

85. Lin, W.; Xing, S.; Jin, Y.; Lu, X.; Huang, C.; Yong, Q. Insight into understanding the performance of deep eutectic solvent pretreatment on improving enzymatic digestibility of bamboo residues. Bioresour. Technol. 2020, 306, 123163. [CrossRef] [PubMed]

86. Xu, G.C.; Ding, J.C.; Han, R.Z.; Dong, J.J.; Ni, Y. Enhancing cellulose accessibility of corn stover by deep eutectic solvent pretreatment for butanol fermentation. Bioresour. Technol. 2016, 203, 364-369. [CrossRef]

87. Zhou, X.; Huang, T.; Liu, J.; Gao, H.; Bian, H.; Wang, R.; Huang, C.; Sha, J.; Dai, H. Recyclable deep eutectic solvent coupling sodium hydroxide post-treatment for boosting woody/herbaceous biomass conversion at mild condition. Bioresour. Technol. 2021, 320, 124327. [CrossRef]

88. Su, Y.; Huang, C.; Lai, C.; Yong, Q. Green solvent pretreatment for enhanced production of sugars and antioxidative lignin from poplar. Bioresour. Technol. 2021, 321, 124471. [CrossRef]

89. Ci, Y.H.; Yu, F.; Zhou, C.X.; Mo, H.E.; Li, Z.Y.; Ma, Y.Q.; Zang, L.H. New ternary deep eutectic solvents for effective wheat straw deconstruction into its high-value utilization under near-neutral conditions. Green Chem. 2020, 22, 8713-8720. [CrossRef]

90. Shen, X.J.; Wang, B.; Huang, P.L.; Wen, J.L.; Sun, R.C. Effects of aluminum chloride-catalyzed hydrothermal pretreatment on the structural characteristics of lignin and enzymatic hydrolysis. Bioresour. Technol. 2016. [CrossRef] [PubMed]

91. Kumar, S.; Sharma, S.; Arumugam, S.M.; Miglani, C.; Elumalai, S. Biphasic Separation Approach in the des Biomass Fractionation Facilitates Lignin Recovery for Subsequent Valorization to Phenolics. ACS Sustain. Chem. Eng. 2020, 8, 19140-19154. [CrossRef]

92. Thulluri, C.; Balasubramaniam, R.; Velankar, H.R. Generation of highly amenable cellulose-I $\beta$ via selective delignification of rice straw using a reusable cyclic ether-assisted deep eutectic solvent system. Sci. Rep. 2021, 11, 1-14. [CrossRef]

93. Loow, Y.L.; Wu, T.Y.; Yang, G.H.; Ang, L.Y.; New, E.K.; Siow, L.F.; Md. Jahim, J.; Mohammad, A.W.; Teoh, W.H. Deep eutectic solvent and inorganic salt pretreatment of lignocellulosic biomass for improving xylose recovery. Bioresour. Technol. 2018. [CrossRef]

94. Fang, C.; Thomsen, M.H.; Frankær, C.G.; Brudecki, G.P.; Schmidt, J.E.; Alnashef, I.M. Reviving Pretreatment Effectiveness of Deep Eutectic Solvents on Lignocellulosic Date Palm Residues by Prior Recalcitrance Reduction. Ind. Eng. Chem. Res. 2017. [CrossRef]

95. Procentese, A.; Johnson, E.; Orr, V.; Garruto Campanile, A.; Wood, J.A.; Marzocchella, A.; Rehmann, L. Deep eutectic solvent pretreatment and subsequent saccharification of corncob. Bioresour. Technol. 2015, 192, 31-36. [CrossRef] [PubMed]

96. Liu, L.; Sun, J.; Cai, C.; Wang, S.; Pei, H.; Zhang, J. Corn stover pretreatment by inorganic salts and its effects on hemicellulose and cellulose degradation. Bioresour. Technol. 2009. [CrossRef]

97. Ma, Y.; Ji, W.; Zhu, X.; Tian, L.; Wan, X. Effect of extremely low $\mathrm{AlCl} 3$ on hydrolysis of cellulose in high temperature liquid water. Biomass Bioenergy 2012. [CrossRef]

98. Di Bitonto, L.; Menegatti, S.; Pastore, C. Process intensification for the production of the ethyl esters of volatile fatty acids using aluminium chloride hexahydrate as a catalyst. J. Clean. Prod. 2019, 239. [CrossRef]

99. Pastore, C.; Barca, E.; Del Moro, G.; Lopez, A.; Mininni, G.; Mascolo, G. Recoverable and reusable aluminium solvated species used as a homogeneous catalyst for biodiesel production from brown grease. Appl. Catal. A Gen. 2016, 501. [CrossRef] 
100. Di Bitonto, L.; Pastore, C. Metal hydrated-salts as efficient and reusable catalysts for pre-treating waste cooking oils and animal fats for an effective production of biodiesel. Renew. Energy 2019, 143, 1193-1200. [CrossRef]

101. Pastore, C.; Lopez, A.; Mascolo, G. Efficient conversion of brown grease produced by municipal wastewater treatment plant into biofuel using aluminium chloride hexahydrate under very mild conditions. Bioresour. Technol. 2014, 155. [CrossRef]

102. Wang, Z.K.; Li, H.; Lin, X.C.; Tang, L.; Chen, J.J.; Mo, J.W.; Yu, R.S.; Shen, X.J. Novel recyclable deep eutectic solvent boost biomass pretreatment for enzymatic hydrolysis. Bioresour. Technol. 2020, 307, 123237. [CrossRef]

103. Lee, K.M.; Hong, J.Y.; Tey, W.Y. Combination of ultrasonication and deep eutectic solvent in pretreatment of lignocellulosic biomass for enhanced enzymatic saccharification. Cellulose 2021. [CrossRef]

104. Schutyser, W.; Renders, T.; Van Den Bosch, S.; Koelewijn, S.F.; Beckham, G.T.; Sels, B.F. Chemicals from lignin: An interplay of lignocellulose fractionation, depolymerisation, and upgrading. Chem. Soc. Rev. 2018, 47, 852-908. [CrossRef] [PubMed]

105. Wang, W.; Gu, F.; Zhu, J.Y.; Sun, K.; Cai, Z.; Yao, S.; Wu, W.; Jin, Y. Fractionation of herbaceous biomass using a recyclable hydrotropic p-toluenesulfonic acid $(\mathrm{p}-\mathrm{TsOH})$ / choline chloride $(\mathrm{ChCl})$ solvent system at low temperatures. Ind. Crops Prod. 2020, 150, 112423. [CrossRef]

106. Gross, A.S.; Bell, A.T.; Chu, J.W. Preferential interactions between lithium chloride and glucan chains in N, N -dimethylacetamide drive cellulose dissolution. J. Phys. Chem. B 2013. [CrossRef] [PubMed]

107. Jørgensen, H.; Kristensen, J.B.; Felby, C. Enzymatic conversion of lignocellulose into fermentable sugars: Challenges and opportunities. Biofuels Bioprod. Biorefin. 2007, 1, 119-134. [CrossRef]

108. Trygg, J.; Fardim, P. Enhancement of cellulose dissolution in water-based solvent via ethanol-hydrochloric acid pretreatment. Cellulose 2011. [CrossRef]

109. Sen, S.; Martin, J.D.; Argyropoulos, D.S. Review of cellulose non-derivatizing solvent interactions with emphasis on activity in inorganic molten salt hydrates. ACS Sustain. Chem. Eng. 2013. [CrossRef]

110. Lindman, B.; Karlström, G.; Stigsson, L. On the mechanism of dissolution of cellulose. J. Mol. Liq. 2010. [CrossRef]

111. Heinze, T.; Koschella, A. Solvents applied in the field of cellulose chemistry: A mini review. Polimeros 2005. [CrossRef]

112. Heinze, T.; Liebert, T. Unconventional methods in cellulose functionalization. Prog. Polym. Sci. 2001, 26, 1689-1762. [CrossRef]

113. Cai, J.; Zhang, L. Rapid dissolution of cellulose in $\mathrm{LiOH} /$ urea and $\mathrm{NaOH} /$ urea aqueous solutions. Macromol. Biosci. 2005. [CrossRef] [PubMed]

114. Brandt, A.; Gräsvik, J.; Hallett, J.P.; Welton, T. Deconstruction of lignocellulosic biomass with ionic liquids. Green Chem. 2013, 15, 550-583. [CrossRef]

115. Zavrel, M.; Bross, D.; Funke, M.; Büchs, J.; Spiess, A.C. High-throughput screening for ionic liquids dissolving (ligno-)cellulose. Bioresour. Technol. 2009. [CrossRef]

116. Francisco, M.; Van Den Bruinhorst, A.; Kroon, M.C. New natural and renewable low transition temperature mixtures (LTTMs): Screening as solvents for lignocellulosic biomass processing. Green Chem. 2012. [CrossRef]

117. Zhang, Q.; Benoit, M.; Dea Oliveiraa Vigier, K.; Barrault, J.; Jérǒme, F. Green and inexpensive choline-derived solvents for cellulose decrystallization. Chem. A Eur. J. 2012, 18, 1043-1046. [CrossRef]

118. Chen, Y.L.; Zhang, X.; You, T.T.; Xu, F. Deep eutectic solvents (DESs) for cellulose dissolution: A mini-review. Cellulose 2019, 26, 205-213. [CrossRef]

119. Lan, W.; Liu, C.F.; Yue, F.X.; Sun, R.C.; Kennedy, J.F. Ultrasound-assisted dissolution of cellulose in ionic liquid. Carbohydr. Polym. 2011. [CrossRef]

120. Ren, H.; Chen, C.; Guo, S.; Zhao, D.; Wang, Q. Synthesis of a Novel Allyl-Functionalized Deep Eutectic Solvent to Promote Dissolution of Cellulose. BioResources 2016, 11, 8535-8547. [CrossRef]

121. Malaeke, H.; Housaindokht, M.R.; Monhemi, H.; Izadyar, M. Deep eutectic solvent as an efficient molecular liquid for lignin solubilization and wood delignification. J. Mol. Liq. 2018. [CrossRef]

122. Chhotaray, P.K.; Biswal, S.K.; Pandey, S. Development of novel hybrid ionic fluids for efficient $\mathrm{CO}_{2}$ capture and cellulose dissolution. J. Mol. Liq. 2020, 312. [CrossRef]

123. Ren, H.; Chen, C.; Wang, Q.; Zhao, D.; Guo, S. The properties of choline chloride-based deep eutectic solvents and their performance in the dissolution of cellulose. BioResources 2016. [CrossRef]

124. Zhou, Y.; Fuentes-Hernandez, C.; Khan, T.M.; Liu, J.C.; Hsu, J.; Shim, J.W.; Dindar, A.; Youngblood, J.P.; Moon, R.J.; Kippelen, B. Recyclable organic solar cells on cellulose nanocrystal substrates. Sci. Rep. 2013. [CrossRef]

125. Zhou, Y.; Khan, T.M.; Liu, J.C.; Fuentes-Hernandez, C.; Shim, J.W.; Najafabadi, E.; Youngblood, J.P.; Moon, R.J.; Kippelen, B. Efficient recyclable organic solar cells on cellulose nanocrystal substrates with a conducting polymer top electrode deposited by film-transfer lamination. Org. Electron. 2014, 15, 661-666. [CrossRef]

126. Clarke, C.J.; Tu, W.C.; Levers, O.; Bröhl, A.; Hallett, J.P. Green and Sustainable Solvents in Chemical Processes. Chem. Rev. 2018, 118, 747-800. [CrossRef] [PubMed]

127. Park, J.H.; Oh, K.W.; Choi, H.M. Preparation and characterization of cotton fabrics with antibacterial properties treated by crosslinkable benzophenone derivative in choline chloride-based deep eutectic solvents. Cellulose 2013, 20, 2101-2114. [CrossRef]

128. Abbott, A.P.; Bell, T.J.; Handa, S.; Stoddart, B. Cationic functionalisation of cellulose using a choline based ionic liquid analogue. Green Chem. 2006, 8, 784-786. [CrossRef]

129. Willberg-Keyriläinen, P.; Hiltunen, J.; Ropponen, J. Production of cellulose carbamate using urea-based deep eutectic solvents. Cellulose 2018, 25, 195-204. [CrossRef] 
130. Sirviö, J.A.; Visanko, M.; Liimatainen, H. Deep eutectic solvent system based on choline chloride-urea as a pre-treatment for nanofibrillation of wood cellulose. Green Chem. 2015, 17, 3401-3406. [CrossRef]

131. Selkälä, T.; Sirviö, J.A.; Lorite, G.S.; Liimatainen, H. Anionically Stabilized Cellulose Nanofibrils through Succinylation Pretreatment in Urea-Lithium Chloride Deep Eutectic Solvent. ChemSusChem 2016, 9, 3074-3083. [CrossRef]

132. Hosseinmardi, A.; Annamalai, P.K.; Wang, L.; Martin, D.; Amiralian, N. Reinforcement of natural rubber latex using lignocellulosic nanofibers isolated from spinifex grass. Nanoscale 2017, 9, 9510-9519. [CrossRef]

133. Liu, Y.; Guo, B.; Xia, Q.; Meng, J.; Chen, W.; Liu, S.; Wang, Q.; Liu, Y.; Li, J.; Yu, H. Efficient Cleavage of Strong Hydrogen Bonds in Cotton by Deep Eutectic Solvents and Facile Fabrication of Cellulose Nanocrystals in High Yields. ACS Sustain. Chem. Eng. 2017, 5, 7623-7631. [CrossRef]

134. Zhang, Y.; Yin, C.; Zhang, Y.; Wu, H. Synthesis and characterization of cellulose carbamate from wood pulp, Assisted by supercritical carbon dioxide. BioResources 2013, 8, 1398-1408. [CrossRef]

135. Mormann, W.; Michel, U. Improved synthesis of cellulose carbamates without by-products. Carbohydr. Polym. 2002, 50, 201-208. [CrossRef]

136. Fu, F.; Xu, M.; Wang, H.; Wang, Y.; Ge, H.; Zhou, J. Improved Synthesis of Cellulose Carbamates with Minimum Urea Based on an Easy Scale-up Method. ACS Sustain. Chem. Eng. 2015, 3, 1510-1517. [CrossRef]

137. Sirviö, J.A.; Heiskanen, J.P. Synthesis of Alkaline-Soluble Cellulose Methyl Carbamate Using a Reactive Deep Eutectic Solvent. ChemSusChem 2017, 10, 455-460. [CrossRef] [PubMed]

138. Sirviö, J.A.; Ukkola, J.; Liimatainen, H. Direct sulfation of cellulose fibers using a reactive deep eutectic solvent to produce highly charged cellulose nanofibers. Cellulose 2019, 26, 2303-2316. [CrossRef]

139. Hu, S.; Zhang, Z.; Zhou, Y.; Han, B.; Fan, H.; Li, W.; Song, J.; Xie, Y. Conversion of fructose to 5-hydroxymethylfurfural using ionic liquids prepared from renewable materials. Green Chem. 2008, 10, 1280-1283. [CrossRef]

140. Assanosi, A.A.; Farah, M.M.; Wood, J.; Al-Duri, B. A facile acidic choline chloride-p-TSA DES-catalysed dehydration of fructose to 5-hydroxymethylfurfural. RSC Adv. 2014, 4, 39359-39364. [CrossRef]

141. Zhang, J.; Xiao, Y.; Zhong, Y.; Du, N.; Huang, X. Alcohol effect and the related mechanism on fructose dehydration into 5-hydroxymethylfurfural in the deep eutectic solvent of [Emim]Cl/alcohol. ACS Sustain. Chem. Eng. 2016, 4, 3995-4002. [CrossRef]

142. Di Bitonto, L.; Antonopoulou, G.; Braguglia, C.; Campanale, C.; Gallipoli, A.; Lyberatos, G.; Ntaikou, I.; Pastore, C. Lewis-Brønsted acid catalysed ethanolysis of the organic fraction of municipal solid waste for efficient production of biofuels. Bioresour. Technol. 2018, 266. [CrossRef]

143. Di Bitonto, L.; Locaputo, V.; D’Ambrosio, V.; Pastore, C. Direct Lewis-Brønsted acid ethanolysis of sewage sludge for production of liquid fuels. Appl. Energy 2020, 259, 114163. [CrossRef]

144. Arslanoğlu, A.; Sert, M. Direct conversion of biomass to platform chemicals, catalyzed using a deep eutectic solvent of N,N diethyl ethanol ammonium chloride-oxalic acid in a microwave reactor. Fuel 2019, 258, 116142. [CrossRef]

145. Arora, S.; Gupta, N.; Singh, V. Choline Based Basic Ionic Liquid (BIL)/Acidic DES Mediated Cellulose Rich Fractionation of Agricultural Waste Biomass and Valorization to 5-HMF. Waste Biomass Valorization 2020, 11, 3345-3354. [CrossRef]

146. Lang, J.; Lu, J.; Lan, P.; Wang, N.; Yang, H.; Zhang, H. Preparation of 5-HMF in a des/ethyl n-butyrate two-phase system. Catalysts 2020, 10, 636. [CrossRef]

147. Qin, Y.Z.; Li, Y.M.; Zong, M.H.; Wu, H.; Li, N. Enzyme-catalyzed selective oxidation of 5-hydroxymethylfurfural (HMF) and separation of HMF and 2,5-diformylfuran using deep eutectic solvents. Green Chem. 2015, 17, 3718-3722. [CrossRef]

148. Chen, B.; Li, Z.; Feng, Y.; Hao, W.; Sun, Y.; Tang, X.; Zeng, X.; Lin, L. Green Process for 5-(Chloromethyl)furfural Production from Biomass in Three-Constituent Deep Eutectic Solvent. ChemSusChem 2021, 14, 847-851. [CrossRef] [PubMed]

149. Zhang, H.; Yu, Z.; Gu, T.; Xiang, L.; Shang, M.; Shen, C.; Su, Y. Continuous Synthesis of 5-hydroxymethylfurfural Using Deep Eutectic Solvents and Its Kinetic Study in Microreactors; Elsevier: Amsterdam, The Netherlands, 2020; Volume 391, ISBN 2154738710.

150. Zuo, M.; Jia, W.; Feng, Y.; Zeng, X.; Tang, X.; Sun, Y.; Lin, L. Effective selectivity conversion of glucose to furan chemicals in the aqueous deep eutectic solvent. Renew. Energy 2021, 164, 23-33. [CrossRef]

151. Ruan, C.; Mo, F.; Qin, H.; Cheng, H.; Chen, L.; Qi, Z. Bifunctional Imidazole-Benzenesulfonic Acid Deep Eutectic Solvent for Fructose Dehydration to 5-Hydroxymethylfurfural. Catal. Lett. 2021, 151, 445-453. [CrossRef]

152. Zuo, M.; Li, Z.; Jiang, Y.; Tang, X.; Zeng, X.; Sun, Y.; Lin, L. Green catalytic conversion of bio-based sugars to 5-chloromethyl furfural in deep eutectic solvent, catalyzed by metal chlorides. RSC Adv. 2016, 6, 27004-27007. [CrossRef]

153. Zuo, M.; Le, K.; Li, Z.; Jiang, Y.; Zeng, X.; Tang, X.; Sun, Y.; Lin, L. Green process for production of 5-hydroxymethylfurfural from carbohydrates with high purity in deep eutectic solvents. Ind. Crops Prod. 2017, 99, 1-6. [CrossRef]

154. Yang, H.; Lang, J.; Lu, J.; Lan, P.; Zhang, H. Study on catalytic conversion of cellulose to 5-hydroxymethyl furfural by directional degradation in deep eutectic solvents. BioResources 2020, 15, 3344-3355. [CrossRef]

155. Sert, M.; Arslanoğlu, A.; Ballice, L. Conversion of sunflower stalk based cellulose to the valuable products using choline chloride based deep eutectic solvents. Renew. Energy 2018, 118, 993-1000. [CrossRef]

156. Shavandi, A.; Jafari, H.; Zago, E.; Hobbi, P.; Nie, L.; De Laet, N. A sustainable solvent based on lactic acid andl-cysteine for the regeneration of keratin from waste wool. Green Chem. 2021, 23, 1171-1174. [CrossRef] 
157. Morais, E.S.; Da Costa Lopes, A.M.; Freire, M.G.; Freire, C.S.R.; Silvestre, A.J.D. Unveiling Modifications of Biomass Polysaccharides during Thermal Treatment in Cholinium Chloride: Lactic Acid Deep Eutectic Solvent. ChemSusChem 2021, 14, 686-698. [CrossRef] [PubMed]

158. Ai, B.; Li, W.; Woomer, J.; Li, M.; Pu, Y.; Sheng, Z.; Zheng, L.; Adedeji, A.; Ragauskas, A.J.; Shi, J. Natural deep eutectic solvent mediated extrusion for continuous high-solid pretreatment of lignocellulosic biomass. Green Chem. 2020, 22, 6372-6383. [CrossRef]

159. Liu, Y.; Friesen, J.B.; McAlpine, J.B.; Lankin, D.C.; Chen, S.N.; Pauli, G.F. Natural Deep Eutectic Solvents: Properties, Applications, and Perspectives. J. Nat. Prod. 2018, 81, 679-690. [CrossRef]

160. Hong, S.; Shen, X.J.; Xue, Z.; Sun, Z.; Yuan, T.Q. Structure-function relationships of deep eutectic solvents for lignin extraction and chemical transformation. Green Chem. 2020, 22, 7219-7232. [CrossRef] 